\title{
Experimental and Theoretical Studies of Cu-Sn Intermetallic Phase Growth During High-Temperature Storage of Eutectic SnAg Interconnects
}

\author{
A. MOROZOV,$^{1,2}$ A.B. FREIDIN, ${ }^{2,3}$ V.A. $\mathrm{KLINKOV}^{3}$ A.V. SEMENCHA, ${ }^{3}$ \\ W.H. MÜLLER, ${ }^{1,5}$ and T. HAUCK ${ }^{4}$
}

1.-Institute of Mechanics, Technische Universität Berlin, Berlin, Germany. 2.-Institute for Problems in Mechanical Engineering of the Russian Academy of Sciences, St. Petersburg, Russia. 3.-Peter the Great St. Petersburg Polytechnic University, St. Petersburg, Russia. 4.-NXP Semiconductors, Schatzbogen 7, 81829 Munich, Germany. 5.—e-mail: wolfgang.h.mueller@tu-berlin.de

In this paper, the growth of intermetallic compound (IMC) layers is considered. After soldering, an IMC layer appears and establishes a mechanical contact between eutectic tin-silver solder bumps and $\mathrm{Cu}$ interconnects in microelectronic components. Intermetallics are relatively brittle in comparison with copper and tin. In addition, IMC formation is typically based on multi-component diffusion, which may include vacancy migration leading to Kirkendall voiding. Consequently, the rate of IMC growth has a strong implication on solder joint reliability. Experiments show that the intermetallic layers grow considerably when the structure is exposed to heat. Mechanical stresses may also affect intermetallic growth behavior. These stresses arise not only from external loadings but also from thermal mismatch of the materials constituting the joint, and from the mismatch produced by the change in shape and volume due to the chemical reactions of IMC formation. This explains why in this paper special attention is being paid to the influence of stresses on the kinetics of the IMC growth. We develop an approach that couples mechanics with the chemical reactions leading to the formation of IMC, based on the thermodynamically sound concept of the chemical affinity tensor, which was recently used in general statements and solutions of mechanochemistry problems. We start with a report of experimental findings regarding the IMC growth at the interface between copper pads and tin based solder alloys in different microchips during a high temperature storage test. Then we analyze the growth kinetics by means of a continuum model. By combining experiment, theory, and a comparison of experimental data and theoretical predictions we finally find the values of the diffusion coefficient and an estimate for the chemical reaction constant. A comparison with literature data is also performed.

Key words: IMC growth, chemical reaction kinetics, high temperature storage test, chemical affinity tensor 


\section{OVERVIEW ON INTERMETALLIC COMPOUND GROWTH}

The main technological process for creating an electrical contact between components in a (micro-) electric circuit is soldering. Different eutectic tinbased alloys containing various metallic chemical elements $(\mathrm{Zn}, \mathrm{Bi}, \mathrm{Pb}, \mathrm{Ag}, \mathrm{Cu}$, etc.) are used for this process. One of the most common lead-free solder alloys in microelectronics is eutectic SnAg3.7. This alloy is also used in ball-grid array (BGA) components in the microelectronic industry for solder bumps and paste. ${ }^{1}$

An intermetallic, also known as an intermetallic compound, intermetallic alloy, ordered intermetallic alloy, and a long-range-ordered alloy is a type of metallic alloy that forms a solid-state compound exhibiting defined stoichiometry and ordered crystal structure, see, e.g., Ref.3. In electric circuits $\mathrm{Cu}$ is used as a conductive material for contacting the surfaces of the electronic components. During soldering the solder material melts and gets in contact with the copper substrate so that a thin layer of a particular Inter-Metallic Compound (IMC) forms at the interface between the $\mathrm{Cu}$ and the tin-based solder. In the absence of an IMC layer the bond between the solder and the substrate is weak, since there is almost no interaction between the metals at the boundary. In $\mathrm{Sn}-\mathrm{Cu}$ and $\mathrm{Sn}-\mathrm{Ag}-\mathrm{Cu}$ eutectic alloys the electrical and mechanical contact is established by one $\left(\mathrm{Cu}_{6} \mathrm{Sn}_{5}\right)$ or two $\left(\mathrm{Cu}_{6} \mathrm{Sn}_{5}\right.$ and $\left.\mathrm{Cu}_{3} \mathrm{Sn}\right)$ intermetallic phases, ${ }^{4}$ respectively. Their formation is determined by the temperature regime, according to the phase diagram shown in Fig. 1. It involves three stages: dissolving of $\mathrm{Cu}$ in liquid $\mathrm{Sn}$, a chemical reaction between the components, and further crystallization. Further growth of the IMC layer takes place in the solid state. The formation of IMCs occurs according to the following chemical reactions between copper and tin,

$$
\begin{aligned}
& 6 \mathrm{Cu}+5 \mathrm{Sn} \rightarrow \mathrm{Cu}_{6} \mathrm{Sn}_{5}, \\
& 3 \mathrm{Cu}+\mathrm{Sn} \rightarrow \mathrm{Cu}_{3} \mathrm{Sn} .
\end{aligned}
$$

$\mathrm{Cu}_{6} \mathrm{Sn}_{5}$ is also referred to as the $\eta$ and $\mathrm{Cu}_{3} \mathrm{Sn}$ as the $\varepsilon$-phase.

As mentioned earlier, the existence of the IMC is a necessary condition for the electro-mechanical contact. However, when compared to pure copper or tin the IMC is more brittle. This may lead to a decrease of the reliability of the joint. In addition, intense diffusion of $\mathrm{Cu}$ (from the pad) or $\mathrm{Sn}$ atoms through the IMC may lead to void formation due to the Kirkendall effect. ${ }^{5}$

There are many experimental studies of the IMC growth in solders of the aforementioned two and other phases of more complex stoichiometry, ${ }^{6-8}$ such as microrelief mapping of the interface, the determination of the chemical composition of the phases, or the influence of the soldering time on the kinetics of the IMC formation, etc. In these systems the growth velocities of the IMC interfaces are much higher than in homogeneously phased solders.

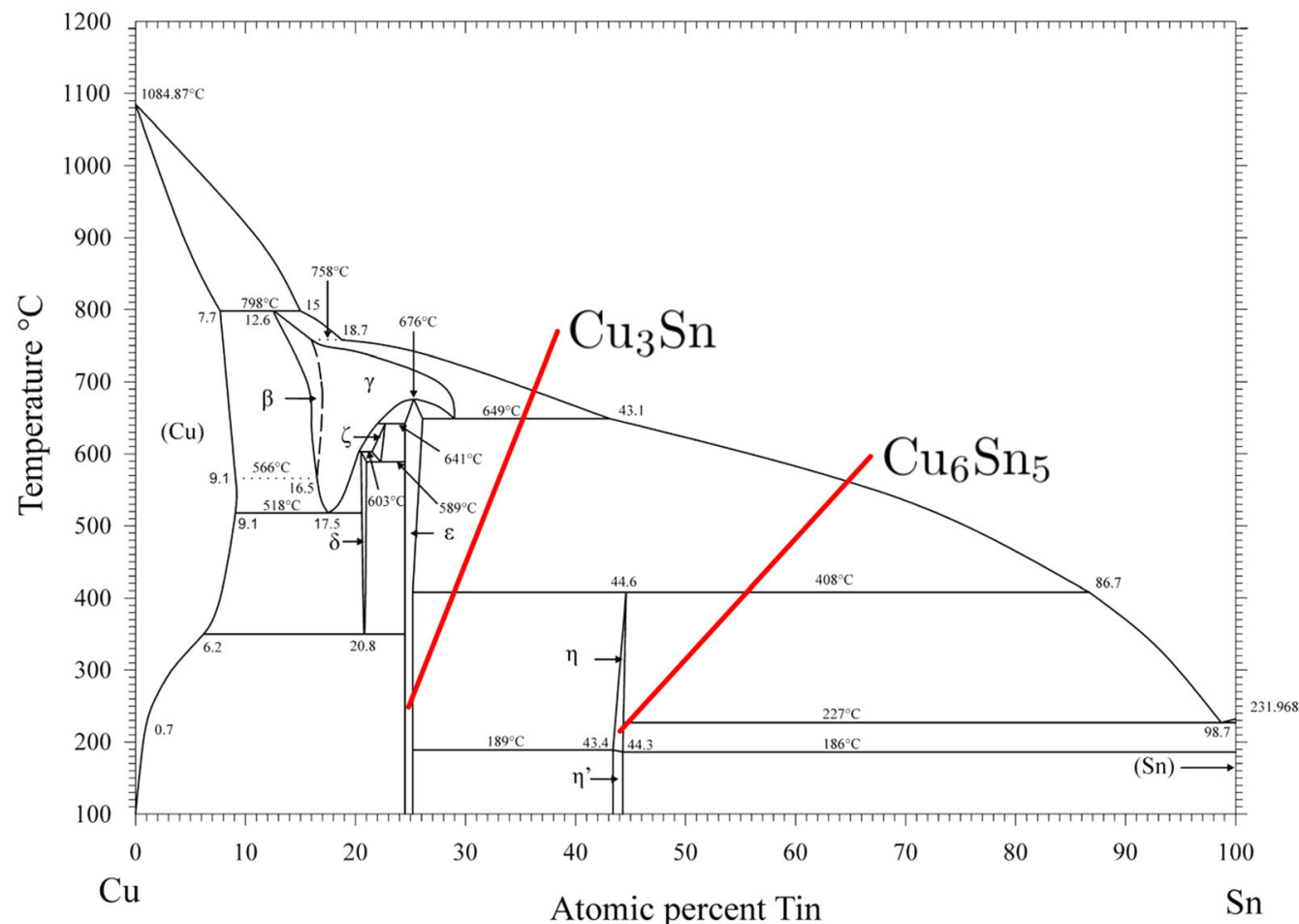

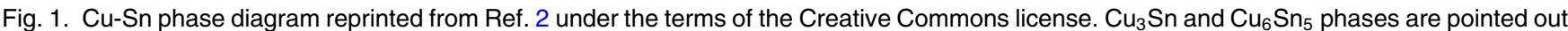
with red lines (Color figure online). 
A typical empirical kinetic equation for the IMC phase growth is based on fitting the experimentally observed data and has the form ${ }^{9,10}$

$$
h=h_{0}+k t^{1 / n},
$$

where $h$ and $h_{0}$ are the current and initial new phase thickness, $t$ is the time, $k$ and $n$ are growth constants. Under the assumption that the major contribution to IMC growth is bulk diffusion, the power law (2) takes the form of a square root dependency (see, e.g., Refs. 11 and 12). In other words, any deviation from the square root behavior indicates that not only bulk diffusion is governing the growth kinetics. ${ }^{9}$ In this case the growth constant $k$ may be expressed through interdiffusion coefficients, $D .{ }^{13}$ The temperature dependence of the latter can be expressed by an Arrhenius equation,

$$
D=D_{0} \exp \left(-\frac{Q}{R T}\right)
$$

where $D_{0}$ is a pre-exponential factor, $Q$ is the reaction activation energy, $R$ is the gas constant, and $T$ is the absolute temperature in $K$, see, e.g., Ref. 14 and the references therein. Based on these ideas a model for intermetallic growth in thin Sn joints between $\mathrm{Cu}$ substrates was proposed in Ref. 15 with application to solder microjoints.

An understanding of the IMC formation process and predicting its kinetics in various range of temperatures is essential for evaluating the structural integrity of solder interconnects. The electrical current during use can heat up a solder bump to $100-150^{\circ} \mathrm{C}$. This heat stimulates IMC growth and as a result reduces the lifetime of the joint.

This paper is organized as follows. In "Experiment Overview" section the experimental procedures are explained. "Experimental Results" section contains the experimental results of the IMC growth including a chemical composition analysis of the IMC layers. A mathematical model for the IMC growth kinetics, which couples mechanical stresses and chemical reaction rate, is presented in "Theoretical Model" section. A simplified model problem is formulated and solved analytically in the same section. A comparison of the experimental and analytical results is also presented in "Theoretical Model" section, resulting in diffusion and reaction coefficients, which can be compared with the literature. Finally, conclusions and an outlook are presented in "Conclusions" section.

\section{EXPERIMENT OVERVIEW}

\section{Specimen Preparation}

Two different types of microchips (referred to as Series I and II in Fig. 2 and in what follows) with BGA packages were available. The solder balls were approximately of the same diameter, $500 \mu \mathrm{m}$. The frames of the microchips were made of plastic or metal for Series I or II, respectively.

For the commercially obtained packages, the exact information about the solder material, the package substrate material, and its surface finish materials, as well the ball attachment process was not available. Clearly, all of this affects the initial IMC formation, as well as the diffusion processes during its growth. Therefore, in order to obtain a somewhat clearer picture, we have carried out our own investigations as follows. According to our EDXS (energy-dispersive x-ray spectroscopy) analysis, no other elements were found in the IMC region apart from $\mathrm{Cu}$ and $\mathrm{Sn}$. Hence, it is fair to assume that the solder material was eutectic tin silver (AgSn), and the substrate had an OSP (organic surface protection) coating. Moreover, note that our experimental work was carried out in order to validate the analytical model of IMC growth but not of its formation. The thickness of the IMC layers was measured before the heat treatment and used as an initial condition for the theoretical model.

In order to reduce the number of tests and still get a reliable statistical data, our experimental procedure to determine the kinetics of the IMC phase growth was organized as follows. Before the experiment each of two types of microchips was dissected through an array of balls, as shown schematically in Fig. 3a. The cross section was polished with $3 \mu \mathrm{m}$ diamond polishing suspension. In order to track the interface propagation, two micro-indenter marks (Vickers method) were applied to each ball by a Buehler MicroMet 5103 microindentation hardness tester. The marks served as reference for tracking the IMC growth interfaces in the neighborhood, Fig. 3b. After the heat treatment and the EDXS analysis, the specimens were returned to the oven. The same cross sections of the same solder balls were examined during the experiment. Note that only three balls per series were continuously monitored during the heat treatment, which was already quite timeconsuming and operationally elaborate. In our curves below showing thickness of IMC over time, an average of the observed growth for the three balls per series is displayed.

This procedure does not allow to fix the specimen in an epoxy casing. Indeed, the melting temperature of the plastic is higher than melting temperature of the solder material. However, the epoxy curing temperature is close to the experimental temperature of $150^{\circ} \mathrm{C}$. Therefore, all polishing was performed "by hand," which resulted in a relatively rough polished surface. Nevertheless, the quality is fair enough to obtain the chemical interface kinetics data, which is the aim of this study. Figure 4 shows the cross section of a solder ball. Differences in contrast correspond to different chemical composition. 

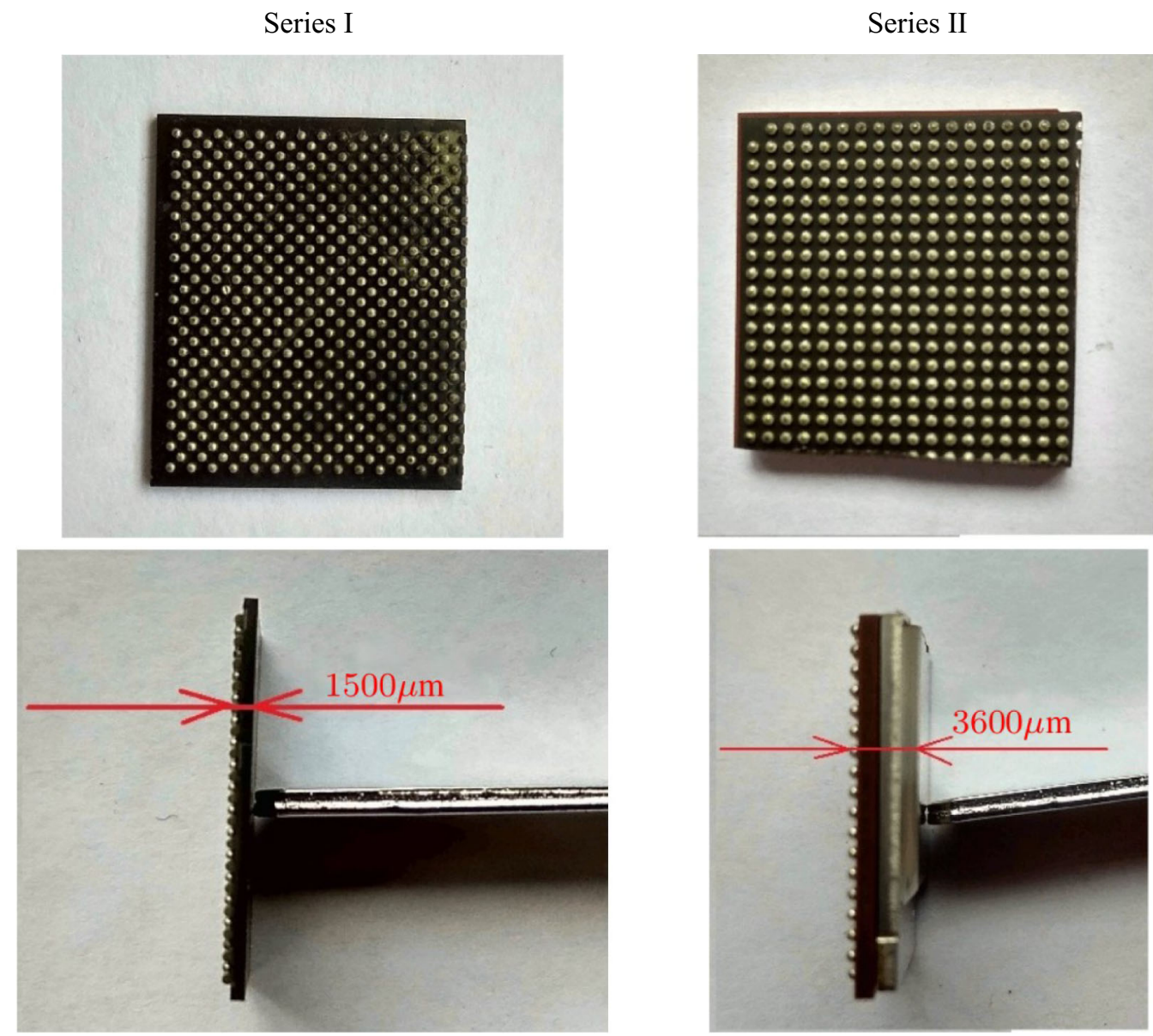

Fig. 2. Photos of the microprocessor boards.

(a)

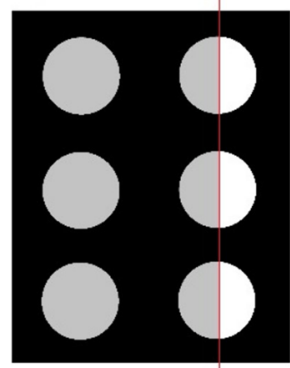

(b)

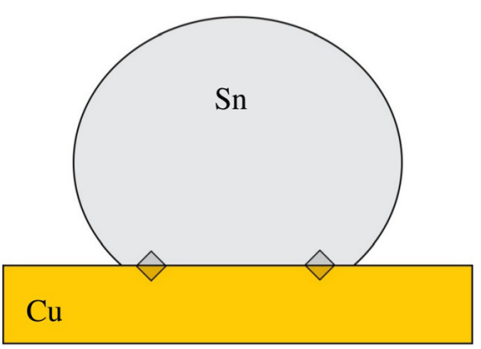

Fig. 3. Cutting scheme applied to the microprocessor (a). Cross section of a solder ball with two micro-indenter marks (b).

\section{Experimental Procedure}

In the current study we analyze the process of IMC growth in microprocessors with BGA packages during a high temperature storage test. According to the JESD22-A103 specification this experiment was performed at $150^{\circ} \mathrm{C}$ in a vacuum oven over $1100 \mathrm{~h}$. The Series I ball was examined after $0 \mathrm{~h}$, $120 \mathrm{~h}, 240 \mathrm{~h}, 360 \mathrm{~h}, 680 \mathrm{~h}$, and $1000 \mathrm{~h}$, and the Series II ball at $0 \mathrm{~h}, 120 \mathrm{~h}, 240 \mathrm{~h}, 360 \mathrm{~h}, 480 \mathrm{~h}$, $800 \mathrm{~h}$, and $1120 \mathrm{~h}$, respectively. The chemical compositions were obtained from EDXS analysis

performed on an Oxford Instruments INCA X-Max detector fitted on a MIRA 3 (TESCAN) microscope at voltage of $20 \mathrm{kV}$. The thickness evaluation was based on postprocessing of micrographs with Python scripts.

\section{EXPERIMENTAL RESULTS}

The results for the two series are qualitatively different even though the corresponding samples were heated and cooled under the same conditions. It is suspected that this is due to the different casings and the associated heat conduction properties: The thickness of the microprocessor case for Series I (plastic casing) was about $150 \mu \mathrm{m}$, and for Series II (metal casing) about $360 \mu \mathrm{m}$. Because of differences in the case materials and their thicknesses for samples of Series I and II, the true cooling rate down to room temperature may differ. Both series of specimens contain a plastic circuit board and BGA in their assembly. However, specimens from Series II have an additional metal framed microchip. Therefore, the cooling time for Series II specimens is longer than for specimens from Series I. The formation of IMC phases is a function of two competing processes, namely growth and dissolution, which in turn depend on the cooling rate. This 
(a)

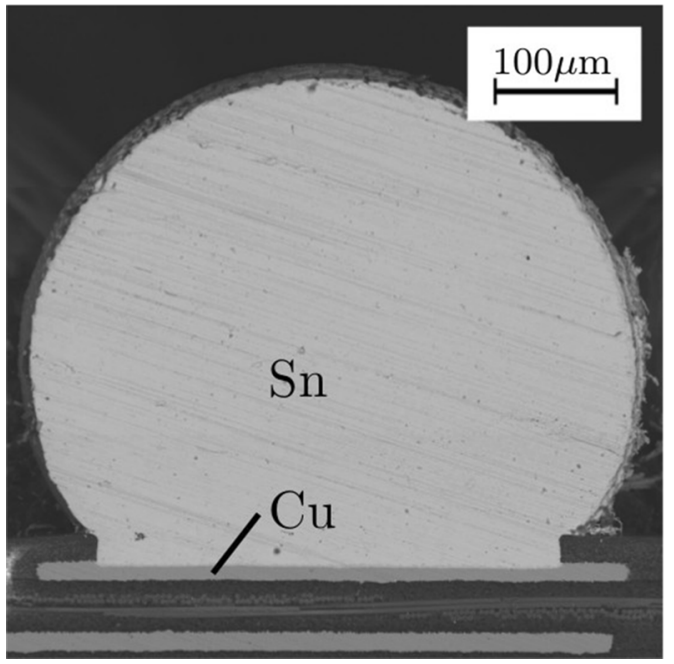

(b)

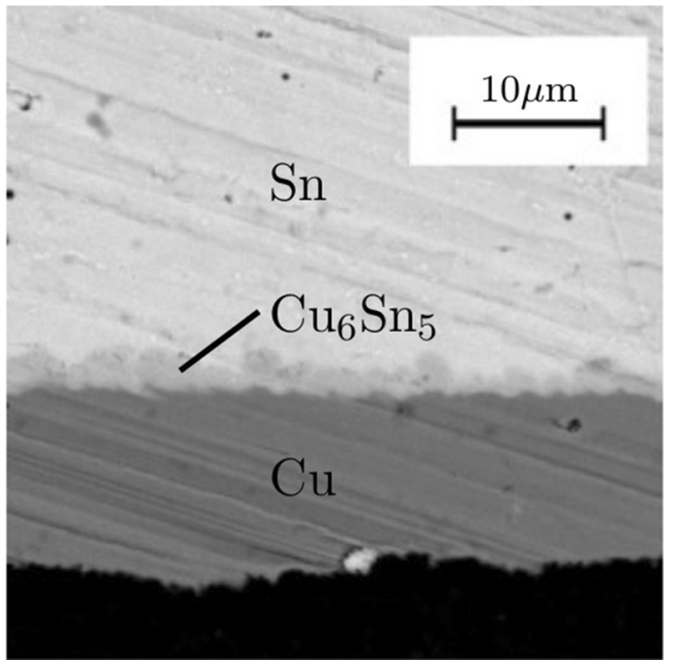

Fig. 4. Cross sections of a solder ball from Series I before heat treatment, general view (a) and interface zone, (b).

may lead to the formation of various phases in microprocessors of various designs.

The right inset of Fig. 4 shows that an IMC layer forms at the copper-solder interface right after the attachment of solder balls on the microprocessor board copper substrates. A spectroscopic analysis showed that its composition corresponds to the compound $\mathrm{Cu}_{6} \mathrm{Sn}_{5}$. Note that the shape of the $\mathrm{Cu}_{6} \mathrm{Sn}_{5}$ layer has a comb-like structure (also referred to as scallops in the literature ${ }^{16}$ ) for all of the studied samples. Its relief is governed by the roughness of the copper substrate, and the initial average height in the samples was in the range 1.9$3.3 \mu \mathrm{m}$. In addition, the tetragonal crystal structure of Sn results in an anisotropy of the diffusivity of the $\mathrm{Cu}$ atoms. ${ }^{17,18}$ It was also shown that the relief depends on the crystalline structure of the underlying copper pad, ${ }^{19-21}$ which can be fine-grained polycrystalline or even single-crystal based.

\section{Chemical Composition of the Compounds}

EDXS analysis was performed at each stage of the experiment in order to obtain the composition of the materials observed through the microscope. The set of examined points for specimens from Series I after $1000 \mathrm{~h}$ heating is shown in Fig. 5 and the corresponding compositions are listed in Table I. All results are given in at.\% (atom percent). One should note that the composition 54.5 at. $\% \mathrm{Cu}$ and 45.5 at.\% $\mathrm{Sn}$ corresponds to $\mathrm{Cu}_{6} \mathrm{Sn}_{5}$ and the composition 75 at. $\% \mathrm{Cu}$ and 25 at. $\% \mathrm{Sn}$ to $\mathrm{Cu}_{3} \mathrm{Sn}$, respectively. From the analyzed data it follows that during heat treatment (up to $1000 \mathrm{~h}$ ) the chemical composition (stoichiometric ratio) of the IMC remained constant and no other intermetallic compounds (e.g., $\mathrm{Cu}_{10} \mathrm{Sn}_{3}$ or $\mathrm{Cu}_{41} \mathrm{Sn}_{11}$ ) were detected.

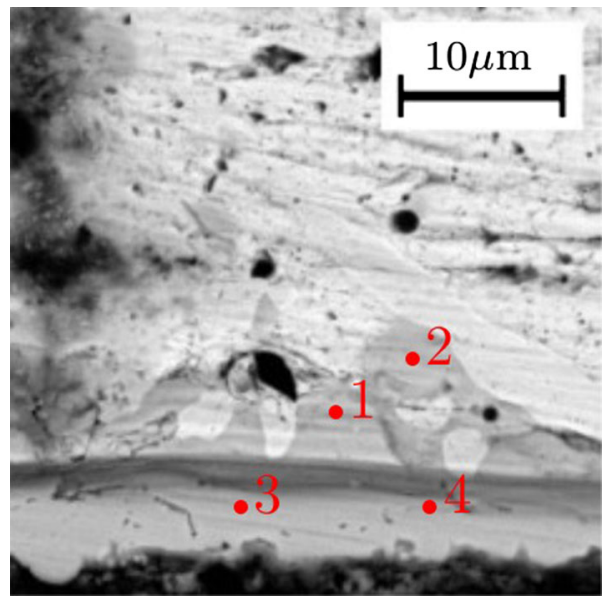

Fig. 5. First set of points from the interface region for EDXS analysis, a ball from Series I at $t=1000 \mathrm{~h}$. The corresponding data is listed in Table I.

Table I. Data obtained from the EDXS analysis for the points in Fig. 5 , values are given in at.\%

\begin{tabular}{lll}
\hline Point & Cu & Sn \\
\cline { 1 - 1 } 1 & 54.5 & 45.5 \\
2 & 52.4 & 47.6 \\
3 & 52.7 & 47.3 \\
4 & 53.1 & 46.9 \\
Average & 53.2 & 46.8 \\
\hline
\end{tabular}

The set of points for the EDXS analysis of the solder material and the $\mathrm{Cu}$ substrate of a specimen from Series I after $1000 \mathrm{~h}$ heating is shown in Fig. 6 and the results of the analysis are listed in Table II. 
Table II. Data obtained from the EDXS analysis for the points in Fig. 6; values are given in at.\%

\begin{tabular}{lcc}
\hline Point & Cu & Sn \\
\cline { 3 - 3 } 1 & 97.4 & 2.6 \\
2 & 94.4 & 5.6 \\
3 & 0.0 & 100.0 \\
4 & 1.0 & 99.0 \\
5 & 9.5 & 90.5 \\
6 & 11.8 & 88.2 \\
\hline
\end{tabular}

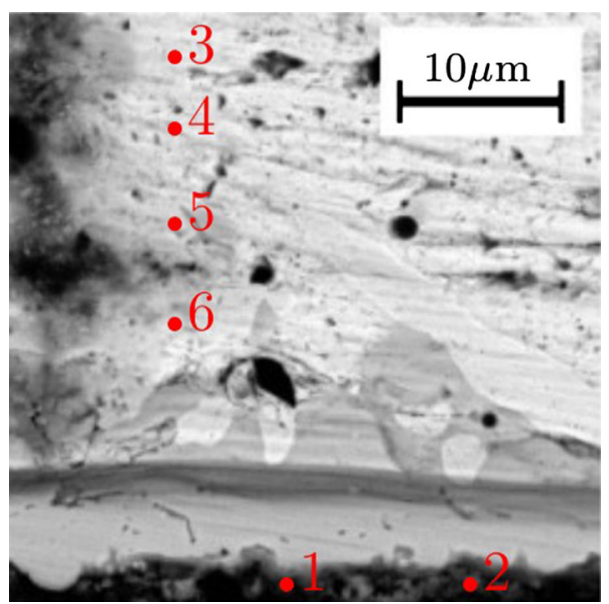

Fig. 6. Second set of points from the interface region for the EDXS analysis, a ball from Series I at $t=1000 \mathrm{~h}$. The corresponding data is listed in Table II.

Points 1 and 2 in Fig. 6 are located in the copper substrate area. However, they contain 2.6 and 5.6 at.\% of Sn, respectively. Moreover, during separation of $\mathrm{Sn}$ atoms from $\mathrm{Cu}_{6} \mathrm{Sn}_{5}$ a reaction proceeds according to the following scheme:

$$
\mathrm{Cu}_{6} \mathrm{Sn}_{5}-3 \mathrm{Sn} \rightarrow 2 \mathrm{Cu}_{3} \mathrm{Sn} .
$$

As a result of Eq. 4 and according to the phase diagram in Fig. 1, a new $\mathrm{Cu}_{3} \mathrm{Sn}$ IMC should then be formed at the $\mathrm{Cu}-\mathrm{Cu}_{6} \mathrm{Sn}_{5}$ interface. However, in Series I this compound was not observed, possibly due to an extremely small thickness of the $\mathrm{Cu}_{3} \mathrm{Sn}$ layer, which could not be detected. We will comment on this issue again in context with our Series II measurements.

The set of examined points for a specimen from Series II after $1120 \mathrm{~h}$ heating is shown in Fig. 7 and the results of the chemical composition analysis are listed in Table III.

It can be seen from Fig. 7 that, unlike Series I, there are no "islands" in the IMC layer and the boundaries of the layers show less roughness (comblike structure). During heat treatment a composition of two IMC configurations was temporarily observed. However, at the later stages of the experiment (after $360 \mathrm{~h}$ ) the $\mathrm{Cu}_{3} \mathrm{Sn}$ phase vanished. The reason for this is unknown. In any case this

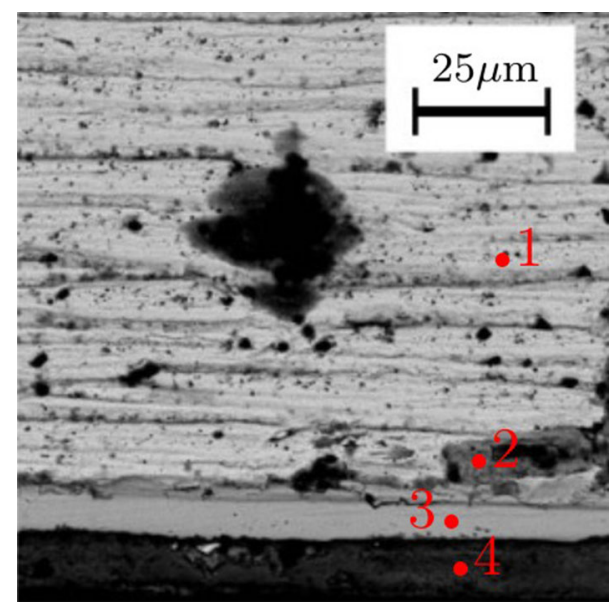

Fig. 7. Set of points from the interface region for the EDXS analysis a ball from Series II at $t=1120 \mathrm{~h}$. The corresponding data is listed in Table III.

Table III. Data obtained from the EDXS analysis for the points in Fig. 7, values are given in at.\%

\begin{tabular}{lcc}
\hline Point & $\mathbf{C u}$ & Sn \\
\cline { 3 - 3 } 1 & 0.0 & 100.0 \\
2 & 31.5 & 68.5 \\
3 & 54.7 & 45.3 \\
4 & 97.0 & 3.0 \\
\hline
\end{tabular}

phase is not so easy to detect; to quote from Ref. 14 "However, it is well known that there is typically a thin layer of $\mathrm{Cu}_{3} \mathrm{Sn}$ present between $\mathrm{Cu}$ and $\mathrm{Cu}_{6} \mathrm{Sn}_{5}$, which, immediately after reflow, is generally only measurable by transmission electron microscopy (TEM), although it can be resolved also by optical microscopy. Based on literature data, we estimate the thickness of the $\mathrm{Cu}_{3} \mathrm{Sn}$ layer to be about $0.1 \mu \mathrm{m} . "$

\section{Thickness Data for the IMC Layers}

In order to determine the characteristics of the growth kinetics of the intermetallic compounds, a set of experiments was conducted using Series I and II BGAs when exposed to a constant temperature. For each series, measurements were carried out as follows.

Heat treatment was performed at a constant temperature of $150^{\circ} \mathrm{C}$. Measurements of the thickness were done at the same location of three balls, namely near the micro-indenter mark. This procedure allows us to track the thickness of the layers at certain points and to average between the balls obtained within each set of microprocessor BGAs.

As it was mentioned above, in the Series I balls only the $\mathrm{Cu}_{6} \mathrm{Sn}_{5}$ phase was detected. It is known from the literature that the formation of the $\mathrm{Cu}_{6} \mathrm{Sn}_{5}$ phase is largely determined by the diffusion 
(a)

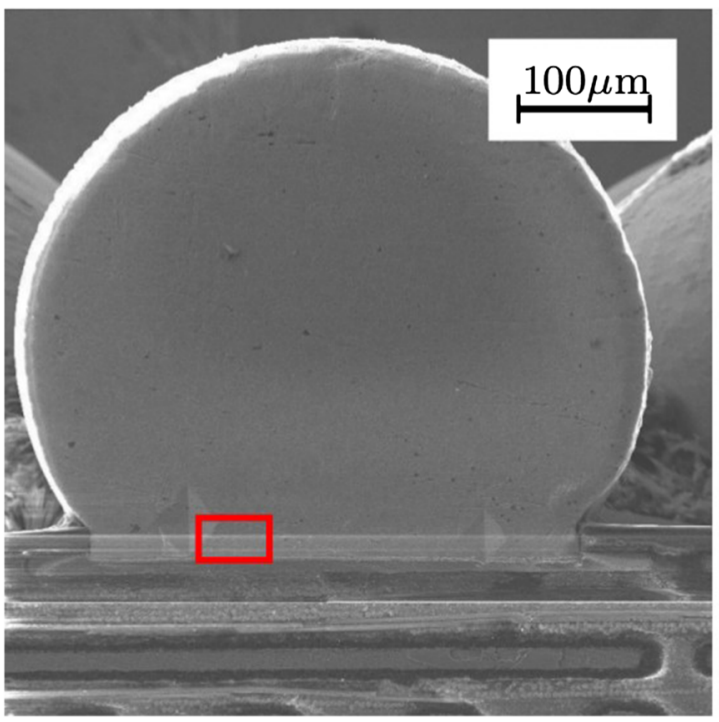

(b)

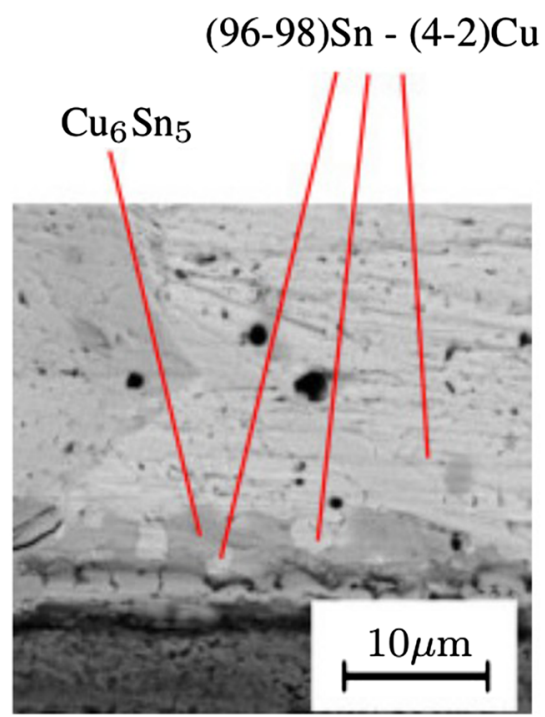

Fig. 8. Cross section of a solder bump from Series I after $t=120 \mathrm{~h}$ heat treatment; general view (a) and enlarged region indicated by the red rectangle (b) (Color figure online).

(a)

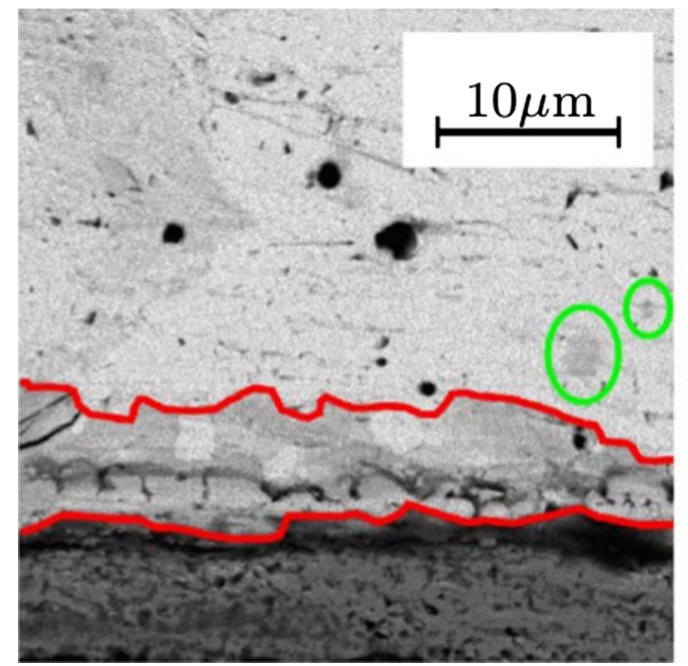

(b)

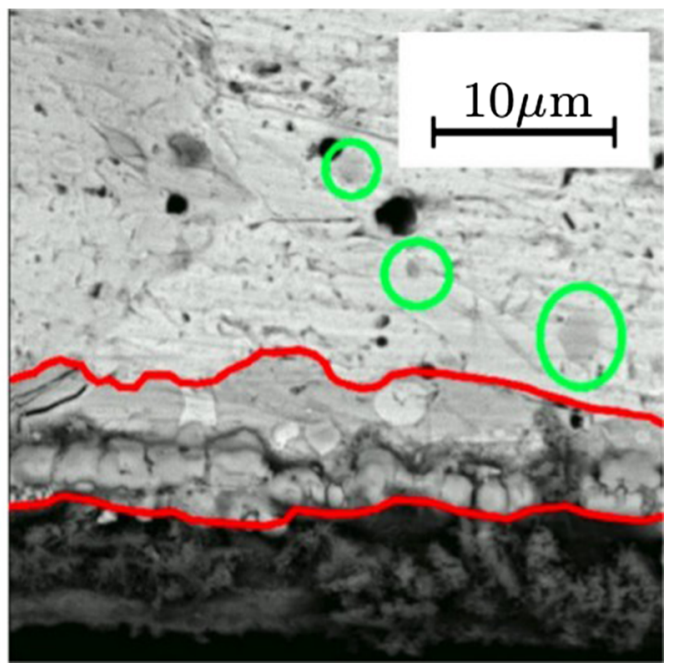

Fig. 9. IMC profiles in the solder bump from Series I after heat treatment: $t=120 \mathrm{~h}(\mathrm{a})$ and $t=240 \mathrm{~h}$ (b). Spheroids of $\mathrm{Cu}_{6} \mathrm{Sn}_{5}$ are marked with green (Color figure online).

processes of Sn, and the diffusion rate determines the thickness of the IMC layer. ${ }^{1,22}$ Figure 8 shows typical micrographs of a sample after $120 \mathrm{~h}$ storage at a constant temperature of $150^{\circ} \mathrm{C}$.

By comparing Fig. 4 (initial state) and Fig. 8, it follows that the thickness of the $\mathrm{Cu}_{6} \mathrm{Sn}_{5}$ layer significantly increased. The comb structure of the IMC phase is preserved. Note that in one set of samples the thickness of $\mathrm{Cu}_{6} \mathrm{Sn}_{5}$ varies along the interface from $3.1 \mu \mathrm{m}$ to $9.1 \mu \mathrm{m}$ (in comparison, the initial layer thickness was $1.9-3.3 \mu \mathrm{m}$, i.e., it increased 2-3 times). A large dispersion of thickness, as well as a formation of IMC agglomerations, can be explained by uneven grain growth rate. ${ }^{23}$
Figure 8 shows that there are local border areas, "islands", in which the initial composition of the solder is preserved.

Intermetallic layers after 120 and $240 \mathrm{~h}$ heat treatment are shown in Fig. 9a, b, respectively. The approximate shape of the interfaces between the solder, IMC and the substrate is outlined in red. One should note that the chemical composition of the IMC remains unchanged and the appearance of new crystalline phases was not detected. The intermetallic compound grows in both directions, toward the solder and toward the substrate. However, the growth rate of the latter is much less than that on the solder side. From Fig. 9 it is also seen that the 
(a)

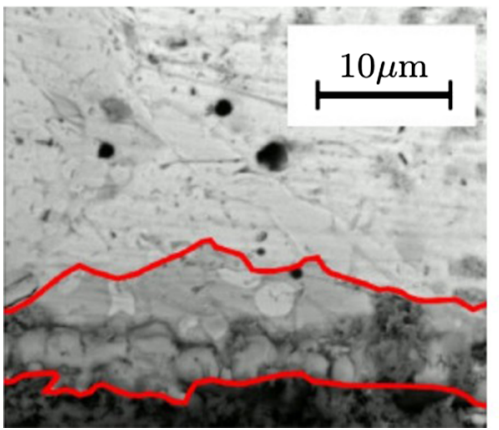

(b)

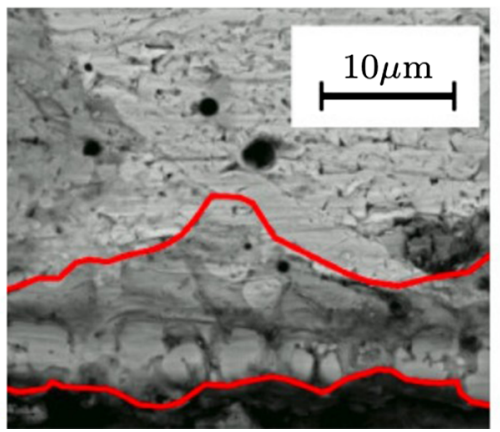

(c)

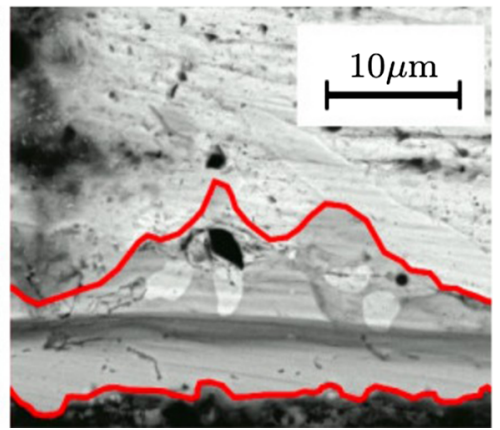

Fig. 10. IMC profiles in a solder bump from Series I after heat treatment: $t=360 \mathrm{~h} \mathrm{(a),} t=680 \mathrm{~h}(\mathrm{~b})$ and $t=1000 \mathrm{~h}(\mathrm{c})$.

(a)

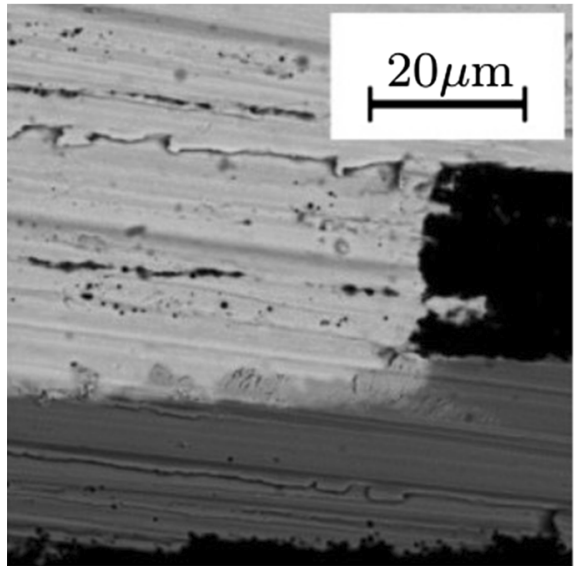

(b)

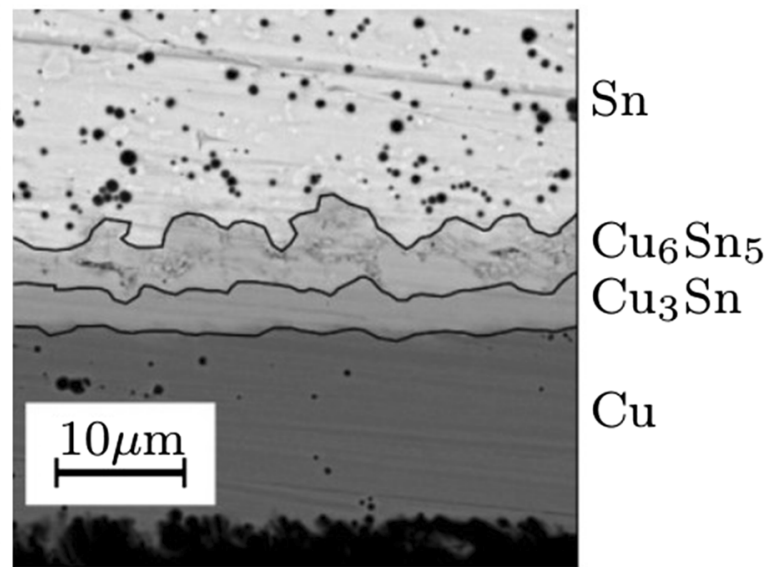

Fig. 11. Cross section of a solder ball from Series II in the interface region before treatment at $t=0$ (a) and after treatment at $t=120 \mathrm{~h}(\mathrm{~b})$.

area of the "island" regions decreases with time, which indicates that the $\mathrm{Cu}_{6} \mathrm{Sn}_{5}$ grains grow in all directions and not only perpendicular to the copper interface.

The dark "island" in the solder area (marked by green color in Fig. 9) are spheroids of $\mathrm{Cu}_{6} \mathrm{Sn}_{5}$ that formed by spalling from the IMC-solder interface. 1,24

Both $\mathrm{Sn}$ and $\mathrm{Cu}_{6} \mathrm{Sn}_{5}$ islands are independent spheroids. We believe that if we polish more material from the surface of the specimen, these spheroids will vanish. Therefore, since these areas do not really belong to the interface, they are not considered, i.e., neither added nor subtracted during further evaluation of the IMC phase thickness.

With further heat treatment a consistent increase in the thickness of the IMC layer is observed. Figure 10 shows the interface profiles at treatment times 360,680 and $1000 \mathrm{~h}$. It can be seen that the formation of a locally thick intermetallic layer occurs. When comparing Fig. 10a, b, it follows that the areas of the solder "islands" slightly increased upon heat treatment. This can be explained by surface effects after the initial cut such that material may have moved out of plane and was then removed during polishing.

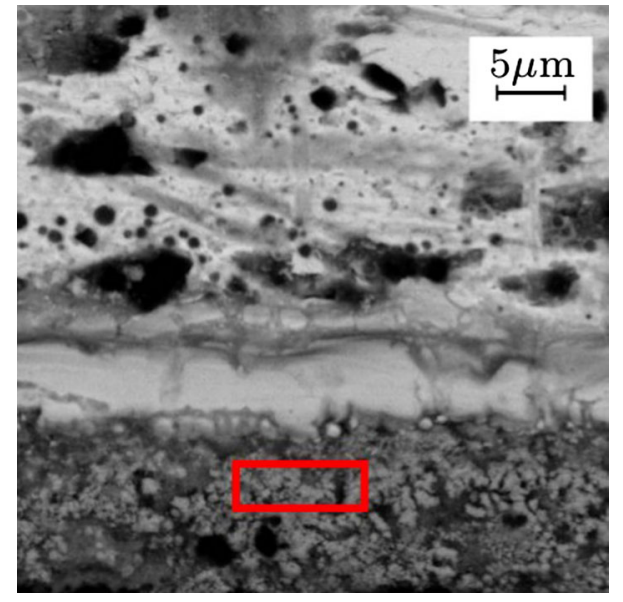

Fig. 12. Cross section of the interface region in a ball from Series II after $480 \mathrm{~h}$ heat treatment. The chemical composition of the marked area obtained by the EDXS analysis is given in Table IV.

Microphotographs for the Series II specimen are shown in Fig. 11 for $0 \mathrm{~h}$ up to $120 \mathrm{~h}$. One should note that for this series the thickness of the IMC layer was less planar than for Series I. The initial thickness of the $\mathrm{Cu}_{6} \mathrm{Sn}_{5}$ phase varied from 1.7 to $4.0 \mu \mathrm{m}$. 
(a)

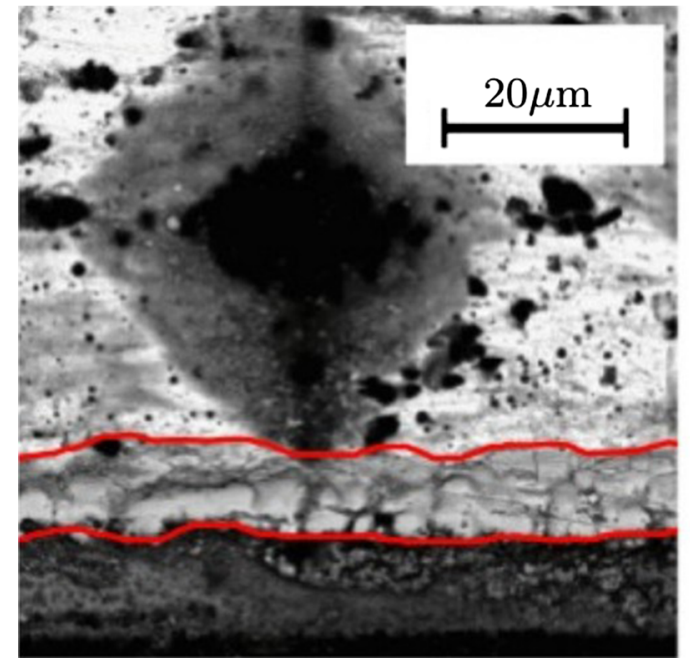

(b)

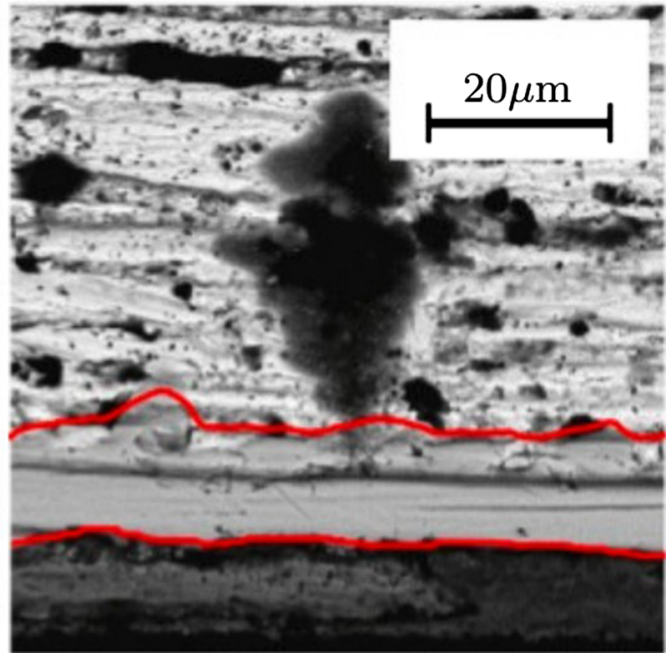

Fig. 13. Cross section of the IMC profile in a solder bump from Series II after heat treatment: $t=800 \mathrm{~h}(\mathrm{a})$ and $t=1120 \mathrm{~h}$ (b).

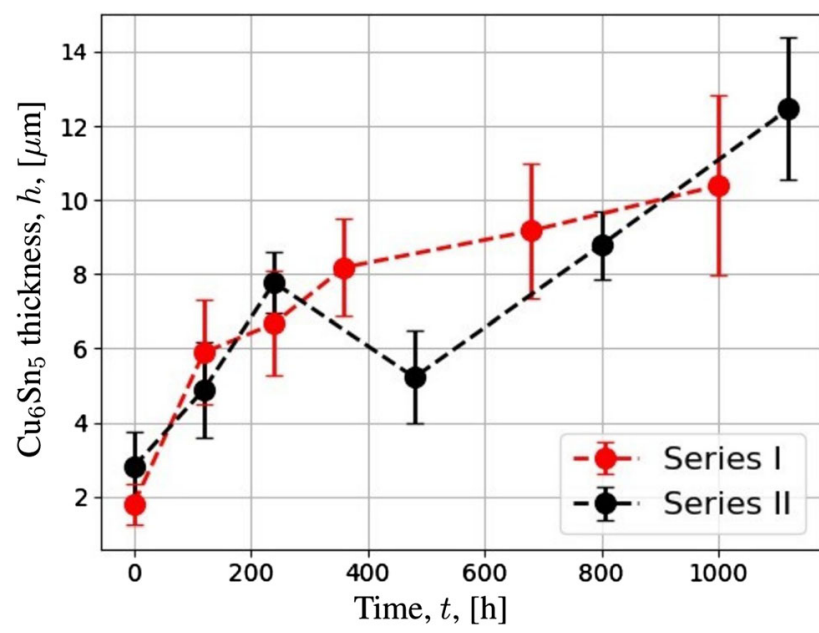

Fig. 14. Growth of the mean thickness of $\mathrm{Cu}_{6} \mathrm{Sn}_{5}$ phase for the specimen from Series I and II. Experimental points are connected by dashed lines for visual clarity only.

As shown in Fig. 11b, two intermetallic phases formed after treatment: $\mathrm{Cu}_{6} \mathrm{Sn}_{5}$ and $\mathrm{Cu}_{3} \mathrm{Sn}$. This is different from the result obtained for balls of Series I. As it is known from the literature the formation of $\mathrm{Cu}_{3} \mathrm{Sn}$ occurs on the interface between the copper substrate and the $\mathrm{Cu}_{6} \mathrm{Sn}_{5}$ compound. The following chemical reaction describes its formation: ${ }^{25}$

$$
\mathrm{Cu}_{6} \mathrm{Sn}_{5}+9 \mathrm{Cu} \rightarrow 5 \mathrm{Cu}_{3} \mathrm{Sn} .
$$

Despite storing in a vacuum oven, oxides and other compounds formed on the surface of the specimen cross sections. This made it hard to evaluate the exact thickness of the $\mathrm{Cu}_{6} \mathrm{Sn}_{5}$ layer for specimens of Series II at time $t=480 \mathrm{~h}$, since part of the layer was covered with other materials ("oxidation dirt"), see Fig. 12.

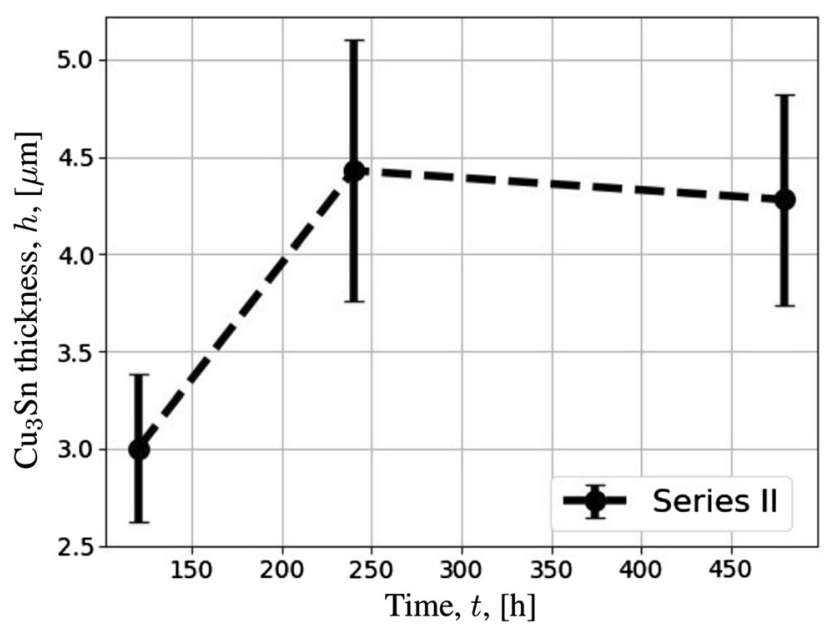

Fig. 15. Growth of the mean thickness of $\mathrm{Cu}_{3} \mathrm{Sn}$ for the specimens from Series I and II. Experimental points are connected by dashed lines for visual clarity only.

The EDXS analysis shows the presence of $4.62 \%$ oxygen in the region where only $\mathrm{Cu}$ is expected (see points 1 and 2 in Fig. 6, or point 4 in Fig. 7). To remove the dirt cover additional polishing was carried out. In the following results, for this particular measurement, the thickness of the only visible IMC layer is presented. However, this measurement is excluded during the analysis for validation of the theoretical model. The thickness of the polished layer can be estimated from Fig. 13, which shows the IMC interface profiles of Series II microchips at the same spot at time $t=800 \mathrm{~h}$ (a) and $t=1120 \mathrm{~h}$ (b). Therefore the thickness of the removed layer is not greater than $10 \mu \mathrm{m}$.

In order to get statistical data about the thickness of the IMC all micrographs were postprocessed with Python scripts. The positions of one interface were subtracted from the other along the specimen. The 


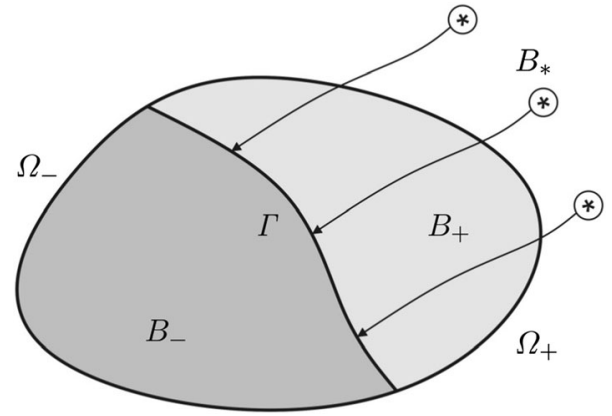

Fig. 16. A solid undergoing a chemical reaction between $B_{-}$and $B_{*}$ localized at the reaction front

mean value was chosen as the current thickness and the standard deviation was obtained in order to obtain an error estimate.

Results for $\mathrm{Cu}_{6} \mathrm{Sn}_{5}$ in Series I and II specimens are shown in Fig. 14. Because of the uneven growth of the IMC layer and its comb-like shape, the standard deviation from the mean value increases in time.

The IMC type $\mathrm{Cu}_{3} \mathrm{Sn}$ was observed only in Series II specimens and even then only for a limited time period. The change of its thickness is shown in Fig. 15. Thus, during annealing for more than $480 \mathrm{~h}$, the $\mathrm{Cu}_{3} \mathrm{Sn}$ phase dissolved, but the mechanism of this process is not understood.

\section{THEORETICAL MODEL}

The novelty of the theoretical part of the present paper is that we model the effects of stresses on the reaction rate with the use of the chemical affinity tensor, which was derived in Ref. 26 and is used in general statements of coupled problems of "diffusion-chemistry-mechanics" (see, e.g., Ref. 27 and references therein). One of the aims of this work is to validate and quantify the model of reaction front kinetics on the basis of the experimental results for the IMC growth.

\section{Chemical Affinity Tensor and General Problem Statement}

The formation of the IMC can be considered a chemical reaction of the following type:

$$
n_{-} B_{-}+n_{*} B_{*} \rightarrow n_{+} B_{+},
$$

where $n_{-}, n_{*}$ and $n_{+}$are the stoichiometric coefficients, $B_{-}, B_{*}$ and $B_{+}$are the chemical formulas of the initial material $(\mathrm{Sn})$, diffusive reactant $(\mathrm{Cu})$, and the reaction product $\left(\mathrm{Cu}_{6} \mathrm{Sn}_{5}\right)$, respectively. The reaction between $B_{-}$and $B_{*}$ is localized at the reaction front $\Gamma$ and is supported by the diffusion of $B_{*}$ through $B_{+}$as schematically shown in Fig. 16 . It is assumed that all delivered $B_{*}$ is consumed by the reaction.

The reaction is accompanied by the change of volume at the reaction front. This deformation produces mechanical stresses at the front which in turn may affect the front propagation. Two sources contribute into the volume change, deformation due to the chemical transformation itself and deformation due to the diffusion of the diffusive reactant (see, e.g., Refs. 26-28). The total deformation can be estimated as follows. A material $B_{-}$is placed on one side of the reaction front and the mix of the materials $B_{+}$and $B_{*}$ is on the other side. Because of the chemical reaction (6), the elementary volume $d V_{-}=n_{-} M_{-} / \rho_{-}$transforms into the volume $d V_{+}=n_{+} M_{+} / \rho_{+}$where $M_{ \pm}$and $\rho_{ \pm}$are the molar masses and reference mass densities of solid reactants $B_{ \pm}$. The ratio of these volumes is

$$
J_{c h}=\frac{n_{+} M_{+} / \rho_{+}}{n_{-} M_{-} / \rho_{-}} .
$$

The diffusion may produce additional volume $\xi n_{*} M_{*} / \rho_{*}$ inside material $B_{+}$, where $M_{*}$ and $\rho_{*}$ are the molar mass and reference mass density of the diffusive reactant $B_{*}$. The parameter $\xi$ reflects the deformational interaction between the reactants $B_{*}$ and $B_{+}$. In fact, from the point view of theory of deformations, $B_{-}$"transforms" into the mix of $B_{+}$ and $B_{*}$ at the interface $\Gamma$. Then the ratio of stressfree volumes of transformed materials coexisting across the reaction front is given by

$$
J_{t r}=\frac{n_{+} M_{+} / \rho_{+}+\xi n_{*} M_{*} / \rho_{*}}{n_{-} M_{-} / \rho_{-}} .
$$

The case $\xi=0$ corresponds to a solid skeleton approach, according to which the diffusion of $B_{*}$ is not accompanied by volume expansion of $B_{+}$. The case $\xi=1$ corresponds to adding the volumes of $B_{+}$ and $B_{*}$. In fact, $\xi$ depends on the mechanism of the diffusion of $\mathrm{Cu}$ and saturations ability of $\mathrm{Cu}_{6} \mathrm{Sn}_{5}$ with respect to diffusive $\mathrm{Cu}$. The diffusion of $\mathrm{Cu}$ through $\mathrm{Cu}_{6} \mathrm{Sn}_{5}$ may occur by vacancy mechanism through two counter fluxes of $\mathrm{Cu}$ and vacancies, and atoms of $\mathrm{Cu}$ take the places of the vacancies. This may also lead to shrinkage of $\mathrm{Cu}_{6} \mathrm{Sn}_{5}$, which corresponds to the case $\xi<0$. By (8), for the reaction (5) between $\mathrm{Sn}$ and $\mathrm{Cu}$ the ratio of volumes we find $J_{t r}=1.44$ (44\% volume expansion) if $\xi=0$ (solid skeleton approach) and $J_{t r}=0.92$ (8\% volume shrinkage) if $\xi=-1$. To our knowledge the question about the value of the transformation strain accompanying IMC formation remains open and estimates of the relative volume change are in the range from $-10 \%,{ }^{13,29,30}$ up to $+44 \%{ }^{31,32}$ Further we fit model parameters for $\xi=-0.5$, which corresponds to volume ratio $J_{t r}=1.18$. In particular, such a value of deformation may be consistent with a small strain approach used in further modeling.

To keep strain compatibility (i.e., continuity of a body) across the reaction front in the presence of volume change $J_{t r}$, additional strains appear and produce internal stresses. These internal stresses together with external loading influence the reaction front velocity. We model stress effects based on 
the concept of the chemical affinity tensor. The notion of the chemical affinity arises from fundamental results by Gibbs and De Donde (see, e.g., Ref. 33). It was shown that in the case of a chemical reaction the factor conjugate to the reaction rate $\omega$ in the expression of the entropy production $P$ multiplied by temperature $T$ was equal to the combination of the chemical potentials of the reaction constituents:

$$
T P=A \omega, \quad A=-\sum n_{k} M_{k} \mu_{k},
$$

where $\mu_{k}$ is the chemical potential of the $k$-th constituent (per unit mass), $M_{k}$ is the molar mass of $k$-th constituent, the stoichiometric coefficient $n_{k}$ contributes to the sum with a positive sign " + " if the $k$-th constituent is produced in the reaction and with a negative sign "-" if the $k$-th constituent is consumed. For the reaction (6) the classical chemical affinity would be

$$
A=n_{-} M_{-} \mu_{-}+n_{*} M_{*} \mu_{*}-n_{+} M_{+} \mu_{+},
$$

where $\mu_{+}, \mu_{-}$and $\mu_{*}$ are the mass densities of the chemical potentials of the constituents $B_{+}, B_{-}$and $B_{*}$, respectively. The factor $A$ was called the chemical affinity of the reaction. Then a kinetic equation in a form of the dependence of the reaction rate on the chemical affinity can be formulated, and one of the accepted dependencies for the reaction is the equation $^{34}$

$$
\omega=\bar{\omega}\left[1-\exp \left(-\frac{A}{R T}\right)\right],
$$

where $\bar{\omega}$ is the so-called partial rate of a direct reaction, which is defined by the concentrations of the reactants, $R$ is the universal gas constant.

The relationships (9)-(11) were formulated for reactions in systems such as gases or liquids for which chemical potentials and, therefore, chemical affinity can be presented as scalar values. The observation that the phase equilibrium and chemical reaction take place not just in a point but at an oriented area element passing through the point, led to the idea of a tensorial nature of the chemical potential and chemical affinity (see the discussion on the tensorial nature of a chemical potential in Ref. 35 and on the tensorial nature of the chemical affinity in Ref. 27). One can see here an analogy to the concept of stress. A stress state is determined by a scalar pressure acting in a point in the case of liquids and gases. However, in the case of a solid, instead of pressure, a stress tensor determines a traction acting at the oriented area element passing through a point.

It was shown that the reaction rate is determined by the normal component $A_{n n}$ of the chemical affinity tensor A, see the derivations in Refs. 26, 36 , and 37], and the chemical affinity tensor has the same mathematical form as the scalar affinity (10) but with tensorial chemical potentials instead of scalar ones. A kinetic equation similar to Eq. 11 can be taken for the reaction rate $\omega_{n}$ at the area element with the normal $\mathbf{n}$ :

$$
\omega_{n}=k_{*} c\left[1-\exp \left(-\frac{A_{n n}}{R T}\right)\right],
$$

where it is taken into account that in the case of the reaction between solid and gaseous constituents $\bar{\omega}$ can be taken in a form $\bar{\omega}=k_{*} c$ where $c$ is the partial molar concentration of the diffusive reactant.

If the reaction rate is found then the normal component of the reaction front velocity $V_{n}$ can be obtained from the mass balance at the reaction front:

$$
V_{n}=\frac{n_{-} M_{-}}{\rho_{-}} \omega_{n}
$$

Mechanical stresses affect the reaction via the normal component of the affinity tensor. In order to handle further analytical calculations and to obtain the unknown parameters of the model, linear elastic solid reactants are considered. In this case the constitutive equations of $B_{-}$and $B_{+}$are

$$
\begin{aligned}
& \boldsymbol{\sigma}_{-}=\mathbf{C}_{-}:\left(\boldsymbol{\varepsilon}_{-}-\alpha_{-} \theta \mathbf{I}\right), \\
& \boldsymbol{\sigma}_{+}=\mathbf{C}_{+}:\left(\boldsymbol{\varepsilon}_{+}-\boldsymbol{\varepsilon}^{t r}-\alpha_{+} \theta \mathbf{I}\right),
\end{aligned}
$$

and the Helmholtz free energies of the solid reactants are represented by

$$
\begin{aligned}
& f_{-}(\varepsilon, \theta)=\eta_{-}+\frac{1}{2}\left(\boldsymbol{\varepsilon}_{-}-\alpha_{-} \theta \mathbf{I}\right): \mathbf{C}_{-}:\left(\boldsymbol{\varepsilon}_{-}-\alpha_{-} \theta \mathbf{I}\right), \\
& f_{+}(\varepsilon, \theta)=\eta_{+}+\frac{1}{2}\left(\boldsymbol{\varepsilon}_{+}-\boldsymbol{\varepsilon}^{t r}-\alpha_{+} \theta \mathbf{I}\right): \mathbf{C}_{+}:\left(\boldsymbol{\varepsilon}_{+}-\boldsymbol{\varepsilon}^{t r}-\alpha_{+} \theta \mathbf{I}\right),
\end{aligned}
$$

where $\mathbf{C}_{ \pm}$are stiffness tensors and $\alpha_{ \pm}$are coefficients of thermal expansion, $\eta_{ \pm}$are the temperature dependent chemical energies of the reactants $B_{ \pm}, \theta$ is the temperature change. For the sake of simplicity we take an isotropic transformation strain tensor

$$
\boldsymbol{\varepsilon}^{t r}=\varepsilon_{t r} \mathbf{I},
$$

where $\varepsilon_{t r}=\left(J_{t r}^{1 / 3}-1\right)$ is the same for all points of the domain occupied by $B_{+}$neglecting differences related with deviations of the concentration of the diffusive reactant.

We also accept that the chemical potential of the diffusive reactant is given by

$$
M_{*} \mu_{*}=\eta_{*}+R T \ln \frac{c}{c_{*}},
$$

where $\eta_{*}$ is the chemical energy of the diffusive constituent $B_{*}$ and $c_{*}$ is a reference concentration of $B_{*}$.

It can be shown (see, e.g., Ref. 36) that from (14)(17) it follows that 


$$
A_{n n}=\frac{n_{-} M_{-}}{\rho_{-}} \chi+n_{*} R T \ln \frac{c}{c_{*}},
$$

where the contribution of mechanical and chemical energies is presented by

$$
\begin{aligned}
\chi= & \gamma+\frac{1}{2} \boldsymbol{\sigma}_{-}:\left(\boldsymbol{\varepsilon}_{-}-\alpha_{-} \theta \mathbf{I}\right) \\
& -\frac{1}{2} \boldsymbol{\sigma}_{+}:\left(\boldsymbol{\varepsilon}_{+}-\boldsymbol{\varepsilon}^{t r}-\alpha_{+} \theta \mathbf{I}\right)+\boldsymbol{\sigma}_{ \pm}: \llbracket \boldsymbol{\varepsilon} \rrbracket
\end{aligned}
$$

(note that due to displacement and traction continuity conditions $\left.\boldsymbol{\sigma}_{-}: \llbracket \boldsymbol{\varepsilon} \rrbracket=\sigma_{+}: \llbracket \varepsilon \rrbracket\right)$, where

$$
\gamma=\eta_{-}-\eta_{+}+\frac{\rho_{-}}{n_{-} M_{-}} n_{*} \eta_{*}
$$

is the combination of the chemical energies of the reactants.

The mechanical stresses $\sigma$ and the concentration $c$ of the diffusing reactant $B_{*}$ can be found from the solution of the system of equations which include:

(i) Mechanical equilibrium equations:

$$
\nabla \cdot \boldsymbol{\sigma}=\boldsymbol{0}
$$

with boundary and interface conditions:

$$
\begin{array}{ll}
\left.\mathbf{u}\right|_{\Omega_{1}}=\mathbf{u}_{0}, & \left.\boldsymbol{\sigma} \cdot \mathbf{n}\right|_{\Omega_{2}}=\mathbf{t}_{0}, \\
\left.\llbracket \mathbf{u} \rrbracket\right|_{\Gamma}=\mathbf{0}, & \left.\llbracket \boldsymbol{\sigma} \rrbracket \cdot \mathbf{n}\right|_{\Gamma}=\mathbf{0},
\end{array}
$$

where $\mathbf{u}_{0}$ and $\mathbf{t}_{0}$ are the given displacement and traction vectors at the corresponding outer boundaries $\Omega_{1}$ and $\Omega_{2}$ of the body; square brackets denote the jump of a value across the reaction front, $\llbracket \phi \rrbracket=\phi_{+}-\phi_{-}$;

(ii) The constitutive equations (14) of the solid reactants;

(iii) The diffusion equation defined over the domain occupied by the material $B_{+}$

$$
\Delta c=0,
$$

with the boundary and interface conditions:

$$
\begin{aligned}
& D \boldsymbol{n} \cdot \nabla c-a\left(c_{*}-c\right)=0 \text { at } \Omega_{+}, \\
& D \boldsymbol{n} \cdot \nabla c+n_{*} \omega_{n}=0 \quad \text { at } \Gamma,
\end{aligned}
$$

where $a$ is the mass transfer coefficient, or the dissolution constant ${ }^{38,39}$ at the outer boundary of the body, $\mathbf{n}$ is the normal directed outward the domain $B_{+}$. For the sake of simplicity we consider the stage of steady-state diffusion with stationary diffusion equation.

The first boundary condition in (24) defines the flux of $B_{*}$ through the external boundary in relation with the solvability of $B_{*}$ in $B_{+}$and means that the supply of $B_{*}$ through the boundary stops if the saturation $c_{*}$ is reached. Of course, one can formally prescribe the Dirichlet boundary condition $c=c_{*}$ at $\Gamma_{+}$. However, the Robin boundary condition $(24)_{1}$ looks more reasonable to us from a physical point of view in the considered case, because of realization.

The second boundary conditions in (24) follows from the mass balance between the supply and consumption of the reactant $B_{*}$ at the reaction front if additionally to take into account that the velocity of diffusive particles is much more than the velocity of the reaction front.

(iv) To close the system of equations one has to add the kinetic equation (12) for $\omega_{n}$ which defines the reaction front velocity via (13) with the dependence of $A_{n n}$ on the stresses and concentration given by (18)-(20).

\section{Analytical Solution of a Model Problem}

As mentioned in the previous sections, only the $\mathrm{Cu}_{6} \mathrm{Sn}_{5}$ intermetallic phase was detected at all stages of the experiment. Therefore, for simplicity of the further analytical analysis, we consider only this IMC. It was pointed out that the interface between $\mathrm{Cu}_{6} \mathrm{Sn}_{5}$ and $\mathrm{Sn}$ moves much faster than one between $\mathrm{Cu}_{6} \mathrm{Sn}_{5}$ and $\mathrm{Cu}$. Therefore, it is also assumed that only the interface between the IMC and the Sn is moving. The maximal thickness of the IMC layer observed in the experiment was about $15 \mu \mathrm{m}$ (Fig. 14) which is much smaller than the diameter of the solder ball (approx. $500 \mu \mathrm{m}$, see Fig. 4). The above gives a reason to consider a simple boundary value problem of mechanochemistry with a plane chemical reaction front propagating in an infinite layer. Similar plane problems for moving interfaces have been previously studied analytically and numerically, see e.g., Refs. 40-42.

Because of the experimental setup, the cross sections of the specimens were stress-free surfaces during the whole experiment. The chemical reaction front propagation was observed at these stress-free surfaces. Strictly speaking, one cannot use either a plane strain or a plane stress simplification in order to find the stresses at the reaction front. Nevertheless, since one can find a kinetic equation for the interface movement for both plane stress and plane strain formulations in a closed form, we solve the model problem in this paper in both formulations, assuming that the real behavior may be somewhat "in between." This gives the opportunity to fit the theoretical prediction with the experimental results, as described in the "Fitting the Model Parameters" section. Based on the fitted data, we further obtain an estimate for the diffusion coefficient and for the chemical reaction kinetic constant.

Consider an elastic layer with a cross section in the $x y$-coordinate plane and the plane reaction front propagating in the $y$-direction from $y=0$ to $y=H$ where $H$ is the layer thickness and $h$ is the current reaction front position (Fig. 17). The storage temperature in the oven is $T$ and the reference temperature is $T_{0}, \theta=T-T_{0}$.

Assume that, by boundary conditions, the upper side of the layer is traction-free, then 


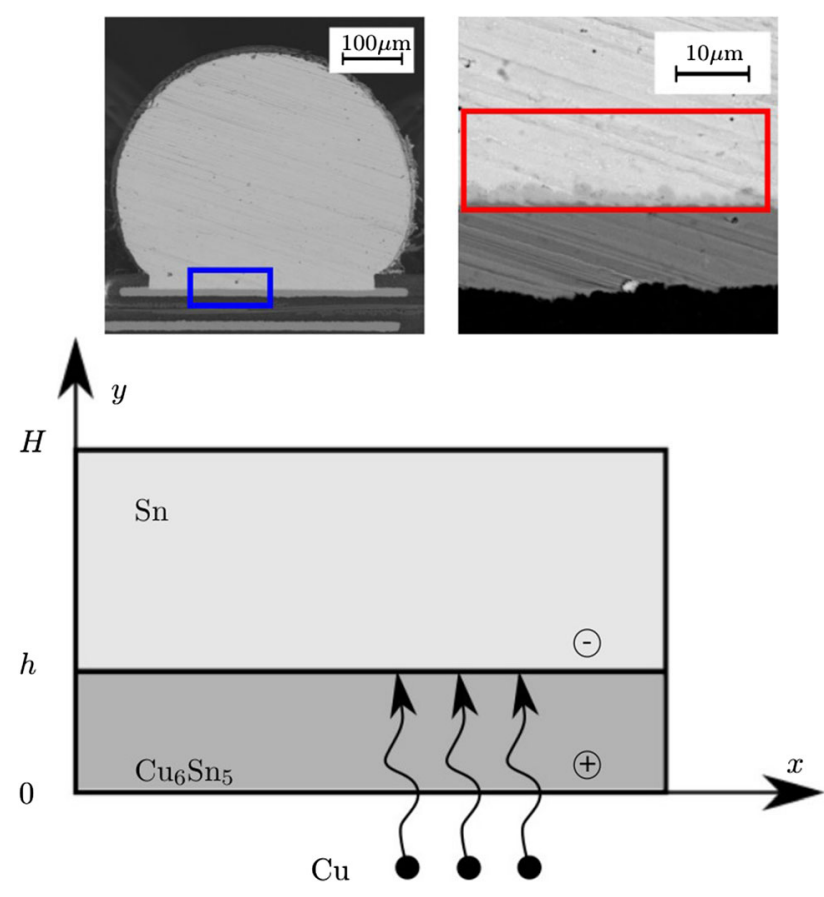

Fig. 17. Model description.

$$
\left.\sigma_{y}^{-}\right|_{y=H}=0,
$$

and the lower side is fixed, then the displacement $\left.\mathbf{u}_{+}\right|_{y=0}=0$. Assume that the displacement is zero in $x$-direction: $u_{x}^{ \pm}=0$ and, thus,

$$
\varepsilon_{x}^{ \pm}=0 \text {. }
$$

The displacement and traction continuity conditions at the reaction front will give, in particular, the continuity of $y$-components of the displacement vector and the stress tensor:

$$
\llbracket u_{y} \rrbracket_{y=h}=0, \quad \llbracket \sigma_{y} \rrbracket_{y=h}=0 .
$$

The plane strain or the plane stress conditions are $u_{z}^{ \pm}=0$ or $\sigma_{z}^{ \pm}=0$, respectively. The equilibrium equations and boundary and interface conditions in both plane statements will be satisfied for zero non-diagonal components of stress and strain tensors, which is why these components are not mentioned above. The displacement continuity condition at the reaction front also demands continuity of $\varepsilon_{z}$, which strictly speaking is not fulfilled in the plane stress formulation, but we neglect the input of this formal incompatibility.

By constitutive equations (14),

$$
\varepsilon_{x}^{ \pm}-\alpha_{ \pm} \theta-\varepsilon_{ \pm}^{t r}=\frac{1}{E_{ \pm}}\left(\sigma_{x}^{ \pm}-v_{ \pm}\left(\sigma_{y}^{ \pm}+\sigma_{z}^{ \pm}\right)\right)
$$

where $E_{ \pm}$and $v_{ \pm}$are the Young's moduli and Poisson's ratio of the materials $B_{ \pm}$, $\varepsilon_{-}^{t r}=0, \quad \varepsilon_{+}^{t r} \equiv \varepsilon^{t r}$. The formulas for $\varepsilon_{y}^{ \pm}$and $\varepsilon_{z}^{ \pm}$follow from (28) by cyclic permutations of $x, y$, and $z$.
Substituting strains and stresses found from (28) by using the conditions (25)-(27) and by taking into account all constraints regarding plane strain and plane stress formulations into (19), we obtain that the contribution $\chi$ in $A_{n n}$ does not depend on the front position, and

$$
\chi= \begin{cases}\gamma+\frac{1}{2} E_{-} \alpha_{-}^{2} \theta^{2}-\frac{1}{2} E_{+}\left(\alpha_{+} \theta+\varepsilon^{t r}\right)^{2}, & \text { plane stress, } \\ \gamma+\frac{E_{-}}{1-v_{-}} \alpha_{-}^{2} \theta^{2}-\frac{E_{+}}{1-v_{+}}\left(\alpha_{+} \theta+\varepsilon^{t r}\right)^{2}, & \text { plane strain. }\end{cases}
$$

Then, by (12), the reaction rate becomes equal to

$$
\omega_{n}=k_{*}\left(c-æ c_{*}\right),
$$

where the stoichiometric coefficient $n_{*}$ is renormalized to one with respect to all other stoichiometric coefficients in (6) $\left(n_{-} \rightarrow n_{-} / n_{*}, n_{+} \rightarrow n_{+} / n_{*}\right)$, and æ is defined as

$$
æ=\exp \left(-\frac{n_{-} M_{-}}{\rho_{-}} \frac{\chi}{R T}\right) .
$$

Diffusive $\mathrm{Cu}$ atoms are supplied through the lower side $y=0$ and the formation of the intermetallic occurs at the interface between $\mathrm{Cu}_{6} \mathrm{Sn}_{5}$ and Sn at $y=h$. The diffusion equation takes the form

$$
\frac{\mathrm{d}^{2} c}{\mathrm{~d} y^{2}}=0, \quad y \in[0, h]
$$

with the boundary conditions

$$
\begin{array}{r}
\left.D \frac{\mathrm{d} c}{\mathrm{~d} y}\right|_{y=h}+\omega_{n}=0, \\
\left.D \frac{\mathrm{d} c}{\mathrm{~d} y}\right|_{y=0}+a\left(c_{*}-c(0)\right)=0,
\end{array}
$$

where $\omega_{n}$ is given by (30).

The solution of the diffusion problem finally gives the concentration at the reaction front as a function of the reaction front position

$$
\left.c\right|_{y=h}=c_{*} \frac{1+æ\left(\frac{k_{*}}{a}+\frac{k_{*} h}{D}\right)}{1+\frac{k_{*}}{a}+\frac{k_{*} h}{D}} .
$$

Then the reaction rate takes a form of the dependence of the front position

$$
\omega_{n}=\frac{k_{*} c_{*}(1-æ)}{1+\frac{k_{*}}{a}+\frac{k_{*} h}{D}} .
$$

Substitution of the expression (35) of the reaction rate into the formula (13) for the interface velocity results in the explicit equation for the dependence of the front position on time:

$$
\frac{\mathrm{dh}}{\mathrm{dt}}=\frac{n_{-} M_{-}}{\rho_{-}} \frac{k_{*} c_{*}(1-\Re)}{1+\frac{k_{*}}{a}+\frac{k_{*} h}{D}} .
$$

Integration yields an explicit dependence of time on the front position: 


$$
t(h)=\frac{\frac{1}{2} \frac{k_{*}}{D}\left(h^{2}-h_{0}^{2}\right)+\left(1+\frac{k_{*}}{a}\right)\left(h-h_{0}\right)}{\frac{n_{-} M_{-}}{\rho_{-}} k_{*} c_{*}(1-æ)},
$$

where $h_{0}$ is the initial thickness of the IMC layer appeared just after the solder bump attachment.

The dependence (37) is rewritten in the standard form of the parabolic law

$$
h(t)=\sqrt{C_{1} t+C_{2}}+C_{3},
$$

where

$$
\begin{aligned}
& C_{1}=2 D \frac{n_{-} M_{-}}{\rho_{-}} c_{*}(1-\circledast), \\
& C_{2}=\left(h_{0}-D\left(\frac{1}{k_{*}}+\frac{1}{a}\right)\right)^{2}, \\
& C_{3}=-D\left(\frac{1}{k_{*}}+\frac{1}{a}\right) .
\end{aligned}
$$

Note that the parameters $k_{*}$ and $a$ occur in (39) only in a combination of the sum of the inverse values. Note also that the influence of mechanical actions is represented by the parameter $æ$, which is constant in the considered case. External mechanical loading may lead to the dependence $æ$ on the front position, which affects the front behavior.

The parabolic law (38) will be used in the next section for fitting parameters to experimental data.

\section{Fitting the Model Parameters}

The mechanical properties of $\mathrm{Cu}, \mathrm{Sn}$ and corresponding IMCs can be found in the literature. Young's modulus, Poisson's ratio, and the coefficient of thermal expansion are listed in Table $\mathrm{V}{ }^{43,44}$ Molar masses and densities are given in Table VI. ${ }^{45}$

The solubility of $\mathrm{Cu}$ in the IMC is defined as the maximum achievable concentration of copper in a $\mathrm{Cu}_{6} \mathrm{Sn}_{5}$ lattice. According to the phase diagram in

\begin{tabular}{|c|c|c|c|c|c|c|}
\hline Element & C & $\mathbf{O}$ & $\mathbf{S i}$ & Cl & $\mathbf{C u}$ & Sn \\
\hline Average at \% & 20.57 & 4.62 & 0.33 & 0.47 & 70.62 & 3.39 \\
\hline
\end{tabular}
Fig. 1 two stable phases can appear in the IMC at $T=150^{\circ} \mathrm{C}: \mathrm{Cu}_{6} \mathrm{Sn}_{5}$ and $\mathrm{Cu}_{3} \mathrm{Sn}$. By the reaction (5)

Table IV. Results of the EDXS analysis of the

\begin{tabular}{|c|c|c|c|}
\hline Material & $\boldsymbol{E}, \mathbf{G P a}$ & $v$ & $\alpha, \mathbf{K}^{-1}$ \\
\hline $\mathrm{Sn}$ & 50 & 0.36 & $22 \times 10^{-6}$ \\
\hline $\mathrm{Cu}_{6} \mathrm{Sn}_{5}$ & 118 & 0.31 & $18 \times 10^{-6}$ \\
\hline
\end{tabular}
marked area in Fig. 12

Table V. Mechanical material properties used in the model. ${ }^{43,44}$ the phase $\mathrm{Cu}_{3} \mathrm{Sn}$ forms when one mole of $\mathrm{Cu}_{6} \mathrm{Sn}_{5}$ reacts with nine moles of $\mathrm{Cu}$. Therefore, we estimate that the maximum amount of copper which can be dissolved in $\mathrm{Cu}_{6} \mathrm{Sn}_{5}$ is $9 \mathrm{~mol}$ of $\mathrm{Cu}$ per $1 \mathrm{~mol}$ of the IMC. In addition, here we assume that diffusive atoms of $\mathrm{Cu}$ do not change the volume of the IMC. Hence, with the aforementioned assumptions and based on the general definition of molar concentration, $c_{*}=9 \rho_{\mathrm{Cu}_{6} \mathrm{Sn}_{5}} / M_{\mathrm{Cu}_{6} \mathrm{Sn}_{5}}=76 \times 10^{-6} \mathrm{~mol} / \mathrm{mm}^{3}$ was computed for the reference value.

As mentioned earlier, the chemical energy parameter $\gamma$ is determined by the $\mathrm{Cu}_{6} \mathrm{Sn}_{5}$ formation energy. This energy is defined empirically. The dependence of this energy on temperature in operating temperatures range can be approximated by Ref. 46

$$
\Delta G=-7747.65-0.371 T \quad(\mathrm{~J} / \mathrm{mol}),
$$

where $T$ is taken in $\mathrm{K}$. In order to calculate $\gamma$, the formation energy has to be divided by the molar volume $V_{\mathrm{Cu}_{6} \mathrm{Sn}_{5}}=11.28 \mathrm{~cm}^{3} / \mathrm{mol}^{47}$ since $\gamma$ unit is an energy density per unit volume.

Certain material and chemical parameters remain unknown, i.e., $D, k_{*}, a$. In order to get an estimate for these values one can try to fit the square root curve, Eq. 38, constraining the parameters such that physically acceptable values for $D$ and $k_{*}$ will result. The fitting process was performed by using weighted least squares, where the weights of the points depend on their estimated error.

It should be noted that the equations proposed in the "Chemical Affinity Tensor and General Problem Statement" section for the chemical reaction front kinetics represent the velocity of the interface in the initial, undeformed configuration, while the micrographs track the position of the interface in the current, deformed configuration. Therefore, before fitting, the analytical curve and the experimental points were transferred to the initial configuration, by multiplying by the corresponding transformation strain value.

The fitting curves for Series I and II specimens are shown in Figs. 18 and 19, respectively.

As it was noted in the "Experiment Overview" section, the specimens of Series II were covered with oxides and other compounds at time $t=480 \mathrm{~h}$ so that a polishing procedure was required. Therefore, it is not surprising that the measured thickness of the IMC layer at that data point departs from the general pattern, Fig. 19, and contains an error that is hard to assess. Because of that, the data point was excluded from the fitting curve procedure. Then the unknown material parameters $D, k_{*}, a$ can be calculated from (39). As it was noted, the kinetic parameter $k_{*}$ and the mass transfer coefficient $a$ appear only in combination, so they cannot be resolved uniquely. Found values of $D$ and the combination $1 / k_{*}+1 / a$ are shown in Table VII.

In Ref. 48 diffusion coefficients of $\mathrm{Cu}$ in the IMCs were calculated based on the measured composition 


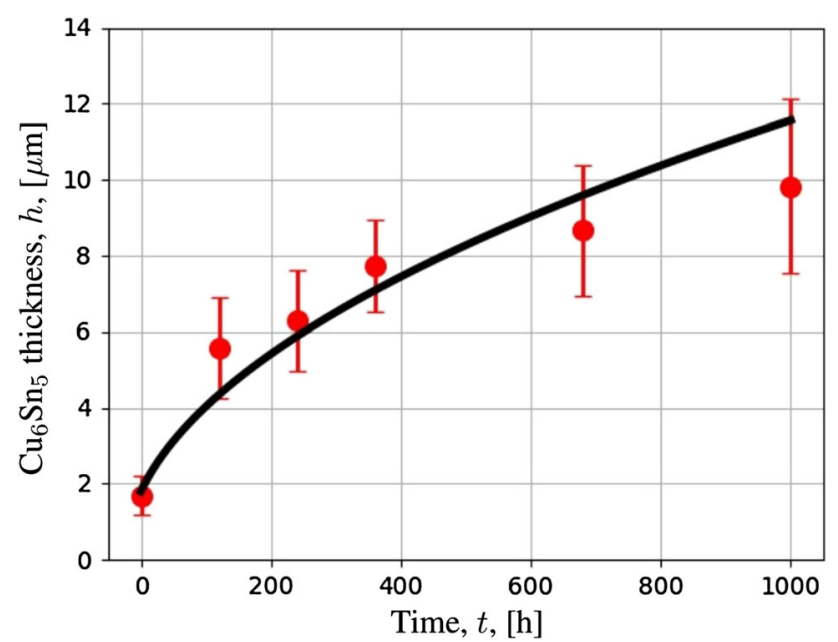

Fig. 18. Fitted square root dependence (38) for Series I specimens.

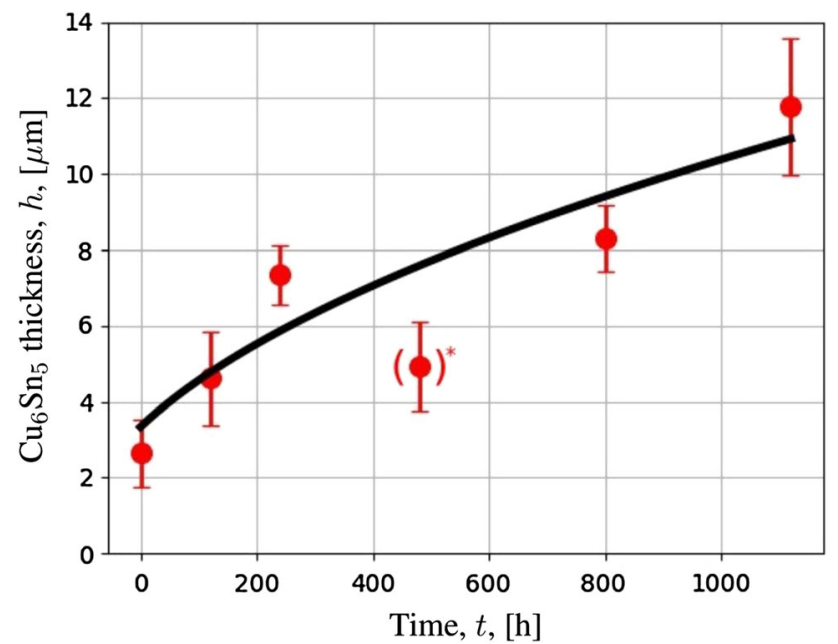

Fig. 19. Fitted square root dependence (38) for Series II specimens. The point marked with asterisk was excluded from the fitting procedure due to bad surface condition of the specimen.

Table VI. Molar masses and densities used in the model. ${ }^{45}$

\begin{tabular}{|c|c|c|c|c|}
\hline & Sn & $\mathbf{C u}$ & $\mathrm{Cu}_{6} \mathrm{Sn}_{5}$ & $\mathrm{Cu}_{3} \mathrm{Sn}$ \\
\hline$\rho, \mathrm{g} / \mathrm{cm}^{3}$ & 7.280 & 8.960 & 8.280 & 9.140 \\
\hline$M, \mathrm{~g} / \mathrm{mol}$ & 118.7 & 63.55 & 974.8 & 309.3 \\
\hline
\end{tabular}

profiles of the diffusion zones within the temperature range of $130-200^{\circ} \mathrm{C}$. The authors showed that the diffusion coefficient depends highly on temperature, stating that $D=0.38 \times 10^{-17} \mathrm{~m}^{2} / \mathrm{s}$ at $T=130^{\circ} \mathrm{C}, D=9.5 \times 10^{-17} \mathrm{~m}^{2} / \mathrm{s}$ at $T=150^{\circ} \mathrm{C}$ and $D=60 \times 10^{-17} \mathrm{~m}^{2} / \mathrm{s}$ at $T=170^{\circ} \mathrm{C}$. Keeping this in mind, one can conclude that obtaining the result of the same order of magnitude can be considered as a good agreement. A comparison of the diffusion parameters, averaged from the two experimental results, with other works is shown in Table VIII.

Both values of diffusion coefficients obtained in this work (basing on plane stress and plane strain formulations) correlate with the data from various papers and can be used as a reference for more complicated models based on the chemical affinity tensor concept. These models can be extended since large strains are involved and non-linear materials as well.

\section{CONCLUSIONS}

A high temperature storage test was carried out for two groups of microchips with eutectic SnAg solder ball grid arrays. The specimens were cut and polished before the heat treatment. The growth of the intermetallic phase was examined by using the same set of solder balls through the entire experiment. The proposed experimental procedure allowed to determine IMC growth kinetics analyzing the small set of specimens. With the use of microindenter marks a relative movement of the IMC interfaces and change of layer thickness were obtained. This in turn lead to the evaluation and quantification of the kinetics of intermetallic growth.

The growth of the $\mathrm{Cu}_{6} \mathrm{Sn}_{5}$ intermetallic compound was modeled analytically based on the chemical affinity tensor concept and by taking temperature dependence into account. The experimental results were used to determine the kinetic parameters in the chemical affinity tensor model for the first time. The simplest model of infinitely wide layers of linear elastic solids was analyzed and a theoretical prediction of the growth kinetics was obtained. The influence of mechanical stresses on IMC growth was taken into account. By comparison of the experimental data with the theoretical model the values of the diffusion coefficient and of the chemical reaction constant were estimated. The obtained diffusion

Table VII. Estimated diffusion coefficient for two series of specimens

\begin{tabular}{|c|c|c|c|c|}
\hline Parameter & Formulation & Series I & Series II & Average \\
\hline$D, \mathrm{~m}^{2} / \mathrm{s}$ & Plane stress & 2.1 & 1.5 & 1.8 \\
\hline$\times 10^{-17}$ & Plane strain & 6.4 & 4.8 & 5.6 \\
\hline $1 / k_{*}+1 / a, \mathrm{~s} / \mathrm{m}$ & Plane stress & 89 & 57 & 73 \\
\hline$\times 10^{-7}$ & Plane strain & 28 & 18 & 23 \\
\hline
\end{tabular}




\begin{tabular}{|c|c|c|c|c|c|c|}
\hline & Ref. 49 & Ref. 50 & Ref. 51 & Ref. 48 & Plane stress & Plane strain \\
\hline$D, \mathrm{~m}^{2} / \mathrm{s} \times 10^{-17}$ & 1.5 & 5.64 & 1.82 & 9.5 & 1.8 & 5.6 \\
\hline
\end{tabular}

coefficients correlate with the results from works of other researchers. The kinetic parameters of the model can now be used as reference values for more general cases with the kinetic equation based on the chemical affinity tensor.

\section{ACKNOWLEDGMENTS}

The authors appreciate the support of the Russian Science Foundation (Grant No. 19-19-00552).

\section{FUNDING}

Open Access funding provided by Projekt DEAL.

\section{CONFLICT OF INTEREST}

The authors declare that they have no conflict of interest.

\section{OPEN ACCESS}

This article is licensed under a Creative Commons Attribution 4.0 International License, which permits use, sharing, adaptation, distribution and reproduction in any medium or format, as long as you give appropriate credit to the original author(s) and the source, provide a link to the Creative Commons licence, and indicate if changes were made. The images or other third party material in this article are included in the article's Creative Commons licence, unless indicated otherwise in a credit line to the material. If material is not included in the article's Creative Commons licence and your intended use is not permitted by statutory regulation or exceeds the permitted use, you will need to obtain permission directly from the copyright holder. To view a copy of this licence, visit http://creativecom mons.org/licenses/by/4.0/.

\section{REFERENCES}

1. L. Lee and A. Mohamad, Adv. Mater. Sci. Eng. 2013, 1 (2013).

2. S. Fürtauer, D. Li, D. Cupid, and H. Flandorfer, Intermetallics 34, 142 (2013).

3. W. D. Callister Jr., D. Rethwisch. Material Science and Engineering: An Introduction, 8th ed. Wiley, New York (2010).
4. O. Liashenko, A. Gusak, and F. Hodaj, J. Mater. Sci.: Mater. Electron. 25, 4664 (2014).

5. V. Dybkov. Reaction Diffusion and Solid State Chemical Kinetics: Handbook, Trans Tech Publications Ltd, Zurich (2010).

6. S. Min-Suk, P. Chan-Jin, and K. Hyuk-Sang, Mater. Chem. Phys. 110, 95 (2008).

7. K. Kim, S. Huh, and K. Suganuma, J. Alloys Compd. 352, 226 (2003).

8. D. Yu, C. Wu, C. Law, L. Wang, and J. Lai, J. Alloys Compd. 392, 192 (2005).

9. S. Cogan, S. Know, J. Klein, and R. Rose, J. Mater. Sci. 19 , 497 (1984).

10. N. Dariavach, P. Callahan, J. Liang, and R. Fournelle, J. Electron. Mater. 35, 1581 (2006).

11. F. Gao, T. Takemoto, H. Nishikawa, and A. Komatsu, J. Electron. Mater. 35, 905 (2006).

12. H. Gao, F. Wei, Y. Sui, J. Qi, Y. He, and Q. Meng, J. Mater. Sci.: Mater. Electron. 30, 2186 (2019).

13. Z. Mei, A. Sunwoo, and J. Morris, Mater. Sci. Eng. A 23, 857 (1992).

14. G. Ross, V. Vuorinen, and M. Paulasto-Kröckel, J. Alloys Compd. 677, 127 (2016).

15. Y. Arafat, H. Yang, I. Dutta, P. Kumar, and B. Datta, J. Electron. Mater. 49, 3367 (2020).

16. H. Kim and K. Tu, Phys. Rev. B 53, 16027 (1996).

17. J. Han, Y. Wang, S. Tan, and F. Guo, J. Electron. Mater. 47, 1705 (2017).

18. Y. Wang, Y. Wang, L. Ma, J. Han, and F. Guo, J. Electron. Mater. 49, 2159 (2020).

19. A. Sunwoo, J. Morris, and G. Lucey, Metall. Mater. Trans. A 23, 1323 (1992)

20. X. Sang, K. Du, and H. Ye, J. Alloys Compd. 469, 129 (2009).

21. K. Suganuma. Lead-Free Soldering in Electronics: Science, Technology, and Environmental Impact (CRC Press, Marcel Dekker, New York, 2003).

22. M. Schaefer, R. Fournelle, and J. Liang, J. Electron. Mater. 27, 1167 (1998).

23. D. Yu and L. Wang, J. Alloys Compd. 458, 542 (2008).

24. A. A. Liu, H. K. Kim, K. N. Tu, and P. A. Totta, J. Appl. Phys. 80, 2774 (1996).

25. X. Hu and Z. Ke, J. Mater. Sci.: Mater. Electron. 25, 936 (2014).

26. A. B. Freidin. In Proceedings of the ASME 2013 International Mechanical Engineering Congress and Exposition, p. V009T10A102 (American Society of Mechanical Engineers, 2013).

27. A. Freidin , E. Vilchevskaya. In: H. Altenbach, A. Öchsner (eds.) Encyclopedia of Continuum Mechanics. Springer, Berlin, pp. 1-17. (2020).

28. W. H. Müller, E. N. Vilchevskaya, and A. B. Freidin, Lecture Notes of TICMI 16, 3 (2015).

29. B.-Z. Lee and D. Lee, Acta Mater. 46, 3701 (1998).

30. S. Bordere, E. Feuillet, J.-L. Diot, R. de Langlade, and J.-F. Silvain, Metall. Mater. Trans B 49, 3343 (2018). 
31. N. Jadhav, E. J. Buchovecky, L. Reinbold, S. Kumar, A. F. Bower, and E. Chason, IEEE Trans. Electron. Packag. Manuf. 33, 183 (2010).

32. B. H. Chudnovsky. Transmission, Distribution, and Renewable Energy Generation Power Equipment. 2nd ed. (CRC Press, Boca Raton, 2017).

33. I. Prigogine and R. Defay. Chemical Thermodynamics (Longmans, Green \& Co, London, 1954).

34. P. Glansdorff and I. Prigogine. Thermodynamic Theory of Stability and Fluctuation (Wiley-interscience, New-York, 1971).

35. M. Grinfeld. Thermodynamic Methods in the Theory of Heterogeneous Systems, Longman Sc \& Tech, London (1991).

36. A. B. Freidin, E. N. Vilchevskaya, and I. Korolev, Int. J. Eng. Sci. 83, 57 (2014).

37. A. B. Freidin, Mechanics of Solids 50, 260 (2015).

38. E. J. Lin, Y. K. Tang, Y. C. Hsu, H. W. Tseng, and C. Y. Liu, J. Appl. Phys. 122, 095702 (2017).

39. M. Xin, W. Fengjiang, Q. Yiyu, and Y. Fusahito, Mater. Lett. 57,3361 (2003).

40. A. B. Freidin, I. K. Korolev, S. P. Aleshchenko, and E. N. Vilchevskaya, Int. J. Fract. 202, 245 (2016).

41. A. Morozov, S. Khakalo, V. Balobanov, A. Freidin, W. Müller, and J. Niiranen, Technische Mechanik 38, 73 (2018).

42. A. Morozov, A. Freidin, W. H. Müller, T. Hauck, I. Schmadlak. In 2018 19th International Conference on Thermal,
Mechanical and Multi-Physics Simulation and Experiments in Microelectronics and Microsystems (EuroSimE), pp. 1-10 (2018). https://doi.org/10.1109/EuroSimE.2018.8369860.

43. P.-F. Yang, Y.-S. Lai, S.-R. Jian, J. Chen, and R. Chen, Mater. Sci. Eng. A 485, 305 (2008).

44. N. Jiang, J. Clum, R. Chromik, and E. Cotts, Scripta Materialia 37, 1851 (1997).

45. F. Sun and Z. Yin, J. Mater. Sci: Mater. Electron. 30, 18878 (2009).

46. L. Huang, W. Jian, B. Lin, Y. Wen, L. Gu, and J. Wang, J. Appl. Phys. 117, 215308 (2015).

47. M. Sobiech, C. Krüger, U. Welzel, J.-Y. Wang, E. J. Mittemeijer, and W. Hügel, J. Mater. Res. 26, 1482 (2011).

48. Y. Yuan, G. Yuanyuan, L. Dajan, and M. Nele, J. Alloys Compd. 661, 282 (2015).

49. M. Onishi and M. Fujibuchi, Trans. Jpn. Inst. Met. 16, 539 (1975).

50. A. Paul, C. Ghosh, and W. Boettinger, Metall. Mater. Trans. A 42A, 952 (2011).

51. S. Kumar, C. Handwerker, and M. Dayanada, J. Phase Equilib. Diffus. 32, 309 (2011).

Publisher's Note Springer Nature remains neutral with regard to jurisdictional claims in published maps and institutional affiliations. 